\title{
Bio-evaluation of fluoro and trifluoromethyl-substituted salicylanilides against multidrug-resistant $S$. aureus
}

\author{
Jhajan Lal ${ }^{1,2} \cdot$ Grace Kaul $^{2,3} \cdot$ Abdul Akhir $^{2,3} \cdot$ Shabina B. Ansari ${ }^{1,2} \cdot$ Sidharth Chopra ${ }^{2,3} \cdot$ Damodara N. Reddy $\mathbb{D}^{1,2}$
}

Received: 23 July 2021 / Accepted: 6 October 2021 / Published online: 27 October 2021

(c) The Author(s), under exclusive licence to Springer Science+Business Media, LLC, part of Springer Nature 2021

\begin{abstract}
Methicillin-resistant Staphylococcus aureus (MRSA) and vancomycin-resistant Staphylococcus aureus (VRSA) are primary causes of skin and soft tissue infections worldwide. To address the emergency caused due to increasing multidrug-resistant (MDR) bacterial infections, a series of novel fluoro and trifluoromethyl-substituted salicylanilide derivatives were synthesized and their antimicrobial activity was investigated. MIC data reveal that the compounds inhibited $S$. aureus specifically (MIC $0.25-64 \mu \mathrm{g} / \mathrm{mL}$ ). The in vitro cytotoxicity of compounds with MIC $<1 \mu \mathrm{g} / \mathrm{mL}$ against Vero cells led to identification of four compounds (20, 22, 24 and 25) with selectivity index above 10. These four compounds were tested against MDR S. aureus panel. Remarkably, 5-chloro$\mathrm{N}$-(4'-bromo-3'-trifluoromethylphenyl)-2-hydroxybenzamide (22) demonstrated excellent activity against nine MRSA and three VRSA strains with MIC $0.031-0.062 \mu \mathrm{g} / \mathrm{mL}$, which is significantly better than the control drugs methicillin and vancomycin. The comparative time-kill kinetic experiment revealed that the effect of bacterial killing of $\mathbf{2 2}$ is comparable with vancomycin. Compound 22 did not synergize with or antagonize any FDA-approved antibiotic and reduced pre-formed S. aureus biofilm better than vancomycin. Overall, study suggested that $\mathbf{2 2}$ could be further developed as a potent anti-staphylococcal therapeutic.
\end{abstract}

\section{Graphical Abstract}

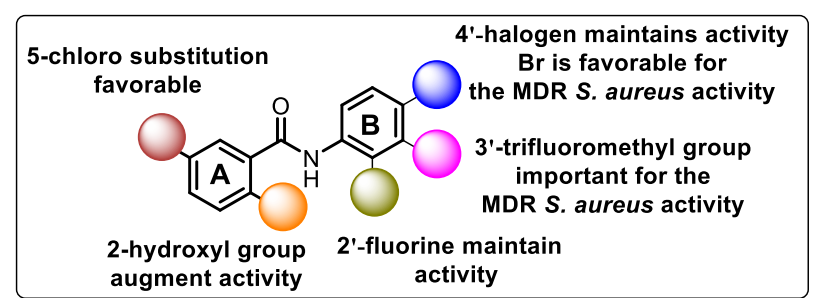

Keywords Methicillin-resistant Staphylococcus aureus • Vancomycin-resistant Staphylococcus aureus •

Fluorosalicylanilides $\cdot$ Trifluoromethyl salicylanilides $\cdot$ Antibacterial $\cdot$ Multidrug-resistant $S$. aureus $\cdot$ Drug repurposing $\cdot$ Biofilm $\cdot$ Drug synergism

These authors contributed equally: Grace Kaul, Abdul Akhir

Supplementary information The online version contains supplementary material available at https://doi.org/10.1007/s00044021-02808-4.

Sidharth Chopra

skchopra007@gmail.com

$\triangle$ Damodara N. Reddy

damodara.reddy@cdri.res.in

1 Medicinal and Process Chemistry Division, CSIR-Central Drug Research Institute Sector 10, Jankipuram Extension, Sitapur Road, Lucknow 226031 Uttar Pradesh, India
2 Academy of Scientific and Innovative Research, New Delhi 110001, India

3 Division of Molecular Microbiology and Immunology, CSIRCentral Drug Research Institute Sector 10, Jankipuram Extension, Sitapur Road, Lucknow 226031 Uttar Pradesh, India 


\section{Introduction}

The unceasing emergence of antimicrobial resistance in bacterial pathogens is a significant threat to global human health [1]. Staphylococcus aureus, a gram-positive, priority II pathogen, is a significant human pathogen that is responsible for causing life-threatening infections, consequently increasing mortality rates in the absence of effective containment and therapeutic solutions [2-4]. S. aureus biofilm formation and persister cells are associated with recurring and difficult to treat infections such as endocarditis, intravenous catheter-related bacteremia, and osteomyelitis [5-7]. The biofilm's extracellular matrix blocks entry of antibiotics and persister cells are dormant, thus making both physiological states as highly antibiotic tolerant [7].

Methicillin-resistant staphylococcus aureus (MRSA) is one of the primary cause of skin and soft tissue infections [8]. Despite the availability of number of antibiotics, effective treatments are very limited for MRSA [9] and include fusidic acid, mupirocin, retapamulin, clindamycin, and vancomycin with other newer drugs such as ceftobiprole, nafithromycin, XF-73, TNP-2092, and ATx201 that are in clinical trials [10]. The situation is getting more worrisome, particularly due to emergence of vancomycinresistant $S$. aureus (VRSA) [2-4]. For successful treatment of infections caused due to multidrug-resistant (MDR) $S$. aureus, discovery and development of new antibiotic molecules with a novel mode of action is an urgent and unmet medical need $[4,11]$.

In search of developing potential anti-infective agents, salicylanilides biological activity profile is well explored in parasitic [12], microbial [13-16], rheumatology [17], and cancer [18]. These compounds also demonstrate potency against various viral pathogens such as SARS-CoV, MERSCoV, SARS-CoV-2, ZIKV, HCV, and human adenovirus $[19,20]$. Salicylanilide family of anthelmintic drugs, e.g., closantel, niclosamide, oxyclozanide, and kinase inhibitor
IMD0354, was recently identified as a potent antistaphylococcals [21-24]. Niclosamide is currently in phase-II clinical trial for the treatment of S. aureus-infected patients (NCT03429595) [10]. However, Niclosamide is known to possess limited aqueous solubility, poor intestinal tract absorption, and low metabolic stability [24, 25]. These features represent significant drawbacks in using Niclosamide for the treatment of systemic bacterial infections. $O$ Alkylamino-tethered niclosamide derivatives have been designed to improve water solubility, but demonstrated poor activity (MIC of $\geq 15 \mu \mathrm{g} / \mathrm{mL}$ ) against colistin-resistant Enterobacteriaceae [26]. These drawbacks motivated us to investigate the impact of fluorine and trifluoromethyl functional group in salicylanilides as potent antistaphylococcals.

The C-F bond has been used as a bioisostere for a number of functional groups, including $\mathrm{C}-\mathrm{H}, \mathrm{C}-\mathrm{OH}$, $\mathrm{C}=\mathrm{O}$, and $\mathrm{CN}$ [27]. The high dissociation energy $(105.4 \mathrm{kcal} / \mathrm{mol})$ of C-F bond is difficult to break and therefore less prone for metabolic transformation [28]. The incorporation of fluorine atoms or fluorinated functional group has become a growing trend in drug development, as it can be used to improve activity, improve bioavailability, and slow metabolic degradation. In recent years, FDA has approved $\sim 20 \%$ of drugs containing fluorine atom or a fluorinated functional group (e.g., trifluoromethyl, $\mathrm{CF}_{3}$ ) [29]. The fluorine containing antibiotics ciprofloxacin, norfloxacin, levofloxacin, linezolid, and eravacycline is currently under clinical utilization (Fig. 1) [10]. However, a recent study has demonstrated maximum gain of fluoroquinolone resistance against MRSA [30] and highlighted a series of side effects such as central nervous system toxicity, cartilage damage, and spermatogenesis impairment [31,32]. Because of insurgence of linezolid-resistant strains, the usage of linezolid is also limited to the hospitalized patients infected with superbugs $[33,34]$. Due to increasing resistance of these
Fig. 1 Representative fluorine containing antibiotics<smiles>O=C(O)c1cn(C2CC2)c2cc(N3CCNCC3)c(F)cc2c1=O</smiles>

Ciprofloxacin

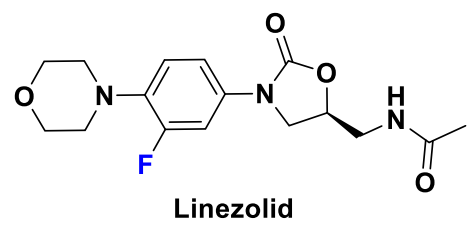

Linezolid<smiles>CCn1cc(C(=O)O)c(=O)c2cc(F)c(N3CCNCC3)cc21</smiles>

Norfloxacin

Levofloxacin<smiles>CCC(C)(C)[C@H](C)O</smiles> 
Scheme 1 Synthesis of salicylanilide derivatives 3-25

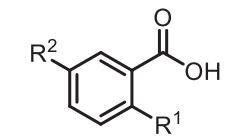

1a: $R^{1}, R^{2}=H$;

1b: $\mathrm{R}^{1}=\mathrm{H}, \mathrm{R}^{2}=\mathrm{Cl}$

1c: $\mathrm{R}^{1}=\mathrm{OH}, \mathrm{R}^{2}=\mathrm{H}$;

1d: $\mathrm{R}^{1}=\mathrm{OH}, \mathrm{R}^{2}=\mathrm{Cl}$<smiles>[R5]c1ccc(N)c([R])c1[R]</smiles>

$\underset{120{ }^{\circ} \mathrm{C}, 3 \mathrm{~h}, 51-96 \%}{\stackrel{\mathrm{PCl}_{3}, \text { Xylene }}{\longrightarrow}}$

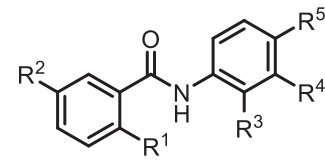

Compounds 3-25

2a: $R^{3}, R^{4}, R^{5}=H ; 2 b: R^{3}, R^{4}=H, R^{5}=F$;

2c: $R^{3}=F, R^{4}, R^{5}=H ; 2 d: R^{3}=H, R^{4}, R^{5}=F$;

2e: $R^{3}=H, R^{4}=C l, R^{5}=F ; 2 f: R^{3}=N_{2}, R^{4}=H, R^{5}=F$;

2g: $\mathrm{R}^{3}=\mathrm{H}, \mathrm{R}^{4}=\mathrm{CF}_{3}, \mathrm{R}^{5}=\mathrm{Br} ; \mathbf{2} \mathbf{h}: \mathrm{R}^{3}=\mathrm{H}, \mathrm{R}^{4}=\mathrm{CF}_{3}, \mathrm{R}^{5}=\mathrm{Cl}$;

2i: $R^{3}=H, R^{4}=C_{3}, R^{5}=H ; 2 j: R^{3}=H, R^{4}=H, R^{5}=C l$;

2k: $R^{3}=H, R^{4}=H, R^{5}=B r$

drugs against MDR $S$. aureus, there is an unmet need to develop newer drugs with higher potency and minimal adverse effects.

Considering the importance of fluorine in medicinal chemistry and growing demand of fluorine containing drugs, we report herein a series of systematically incorporated fluoro and trifluoromethyl salicylanilide derivatives that were synthesized and investigated their activity against MDR $S$. aureus to identify a potential therapeutic option. Structure-activity relationship (SAR) of fluoro and trifluoromethyl salicylanilide derivatives was examined to identify a new hit molecule for the treatment of MDR $S$. aureus infections with increased antimicrobial potency and low toxicity.

\section{Results and discussions}

\section{Chemistry}

The fluoro and trifluoromethyl-substituted salicylanilides and other derivatives synthesis is shown in Scheme 1 and synthesis was accessed in one-pot condensation reaction. Substituted salicylic or benzoic acid (1a-d) was treated with substituted anilines $(\mathbf{2} \mathbf{a}-\mathbf{k})$ in the presence of phosphorous trichloride in mixture of xylenes at $120{ }^{\circ} \mathrm{C}$ for $3 \mathrm{~h}$. No side products were observed during the reaction and all compounds were isolated without column chromatography. Filtration and washing with hot water $\left(70{ }^{\circ} \mathrm{C}\right)$ and $10 \%$ ethanol in water gave the desired salicylanilides 3-25 in high purity (Table 1). All synthesized compounds were characterized by NMR, HRMS, and ESI. The purity of synthesized compounds was determined by analytical highperformance liquid chromatography (HPLC).

\section{Biological evaluation}

The initial antimicrobial screening was performed against panel of five clinically relevant bacterial strains namely: (1) Escherichia coli ATCC 25922, (2) Klebsiella pneumoniae BAA 1705, (3) Pseudomonas aeruginosa ATCC 27853, (4) Acinetobacter baumannii BAA 1605, and (5) S. aureus ATCC 29213. The MIC data are shown in Table 2 and reveal that the synthesized salicylanilide derivatives $(\mathbf{3}-\mathbf{2 5})$ inhibited $S$. aureus ATCC 29213 specifically (MIC $0.25-64 \mu \mathrm{g} / \mathrm{mL}$ ) and did not exhibit any gram-negative bacterial coverage (Table 2).

As it can be seen in Table 2, benzanilide (3) and 5-chlorobenzanilide (4) demonstrated no growth inhibition, while salicylanilide (5) and 5-chloro salicylanilide (6) inhibited S. aureus ATCC 29213 at 64 and $8 \mu \mathrm{g} / \mathrm{mL}$, respectively. These preliminary results are comparable with the reported activity of benzanilide derivatives [1316]. Fluorine substitution at $2^{\prime}$ or $4^{\prime}$ position in salicylanilides 7 and 9 exhibited improved potency $(32 \mu \mathrm{g} / \mathrm{mL})$. More interestingly, ten-fold increased activity observed in 5-chloro- $N$-(2'/4'-fluorophenyl)-salicylanilides 8 and 10 ( 2 and $4 \mu \mathrm{g} / \mathrm{mL}$, respectively). As expected with the reported results $[13,22]$, the activity improved on substitution of chlorine at 5-position in salicylanilides and same trend was observed in entire series (Table 2).

Based on these preliminary results, we fixed chlorine at the fifth position in salicylic acid and varied the substitution on aniline ring. The activity was further improved eight-fold in $\mathbf{1 1}$ and $12(0.44 \mu \mathrm{g} / \mathrm{mL})$, in which additional fluorine and chlorine was incorporated at $3^{\prime}$-position in compound $\mathbf{8}$, indicating that substitution at 3'-position improves activity. The activity diminished in 2'-nitro-4'-fluoro substituted compounds $\mathbf{1 5}$ and 16 (MIC 32 and $3.88 \mu \mathrm{g} / \mathrm{mL}$, respectively). However, activity improved four-fold in 17 and 18 (MIC 2 and $1 \mu \mathrm{g} / \mathrm{mL}$, respectively) on exchanging nitro and fluoro substituent positions in $\mathbf{1 5}$ and 16. More interestingly, 3'-trifluoromethylsubstituted salicylanilides 19-23 (MIC $0.25-0.5 \mu \mathrm{g} / \mathrm{mL}$ ) showed improved activity. In the absence of 3'-trifluoromethyl substitution, reduction in activity was observed in compounds 24 and 25. Overall eight compounds inhibited $S$. aureus ATCC 29213 with MIC below $1 \mu \mathrm{g} / \mathrm{mL}$.

Next, we examined in vitro cytotoxicity of active compounds (MIC $<1 \mu \mathrm{g} / \mathrm{mL}$ ) against Vero cells (ATCC CCL81) using MTT assay to determine the selectivity index (SI) of active compounds. The SI of at least $>10$ is considered to be essential to take the compound forward for pre-clinical development. As summarized in Table 2, four compounds 20, 22, 24, and 25 demonstrated SI $>10$, thus indicating the specificity of these compounds toward bacterial rather than host cells. 
Table 1 Synthesized salicylanilide derivatives (3-25) yield and HPLC purity

\begin{tabular}{lllllllll}
\hline S. no. & Compound code & $\mathrm{R}^{1}$ & $\mathrm{R}^{2}$ & $\mathrm{R}^{3}$ & $\mathrm{R}^{4}$ & $\mathrm{R}^{5}$ & Yield (\%) & HPLC purity (\%) \\
\hline 1 & $\mathbf{3}$ & $\mathrm{H}$ & $\mathrm{H}$ & $\mathrm{H}$ & $\mathrm{H}$ & $\mathrm{H}$ & 73 & $>99$ \\
2 & $\mathbf{4}$ & $\mathrm{Cl}$ & $\mathrm{H}$ & $\mathrm{H}$ & $\mathrm{H}$ & $\mathrm{H}$ & 89 & $>99$ \\
3 & $\mathbf{5}$ & $\mathrm{H}$ & $\mathrm{OH}$ & $\mathrm{H}$ & $\mathrm{H}$ & $\mathrm{H}$ & 83 & $>99$ \\
4 & $\mathbf{6}$ & $\mathrm{Cl}$ & $\mathrm{OH}$ & $\mathrm{H}$ & $\mathrm{H}$ & $\mathrm{H}$ & 84 & 97.7 \\
5 & $\mathbf{7}$ & $\mathrm{H}$ & $\mathrm{OH}$ & $\mathrm{H}$ & $\mathrm{H}$ & $\mathrm{F}$ & 60 & $>99$ \\
6 & $\mathbf{8}$ & $\mathrm{Cl}$ & $\mathrm{OH}$ & $\mathrm{H}$ & $\mathrm{H}$ & $\mathrm{F}$ & 66 & $>99$ \\
7 & $\mathbf{9}$ & $\mathrm{H}$ & $\mathrm{OH}$ & $\mathrm{F}$ & $\mathrm{H}$ & $\mathrm{H}$ & 59 & 98.1 \\
8 & $\mathbf{1 0}$ & $\mathrm{Cl}$ & $\mathrm{OH}$ & $\mathrm{F}$ & $\mathrm{H}$ & $\mathrm{H}$ & 65 & $>99$ \\
9 & $\mathbf{1 1}$ & $\mathrm{H}$ & $\mathrm{OH}$ & $\mathrm{H}$ & $\mathrm{F}$ & $\mathrm{F}$ & 71 & $>99$ \\
10 & $\mathbf{1 2}$ & $\mathrm{Cl}$ & $\mathrm{OH}$ & $\mathrm{H}$ & $\mathrm{F}$ & $\mathrm{F}$ & 51 & $>99$ \\
11 & $\mathbf{1 3}$ & $\mathrm{H}$ & $\mathrm{OH}$ & $\mathrm{H}$ & $\mathrm{Cl}$ & $\mathrm{F}$ & 96 & $>99$ \\
12 & $\mathbf{1 4}$ & $\mathrm{Cl}$ & $\mathrm{OH}$ & $\mathrm{H}$ & $\mathrm{Cl}^{2}$ & $\mathrm{~F}$ & 75 & 98.3 \\
13 & $\mathbf{1 5}$ & $\mathrm{H}$ & $\mathrm{OH}$ & $\mathrm{NO}_{2}$ & $\mathrm{H}$ & $\mathrm{F}$ & 62 & $>99$ \\
14 & $\mathbf{1 6}$ & $\mathrm{Cl}$ & $\mathrm{OH}$ & $\mathrm{NO}_{2}$ & $\mathrm{H}$ & $\mathrm{F}$ & 67 & $>99$ \\
15 & $\mathbf{1 7}$ & $\mathrm{H}$ & $\mathrm{Cl}$ & $\mathrm{F}$ & $\mathrm{H}$ & $\mathrm{NO}$ & 53 & $>99$ \\
16 & $\mathbf{1 8}$ & $\mathrm{Cl}$ & $\mathrm{H}$ & $\mathrm{F}$ & $\mathrm{H}$ & $\mathrm{NO}$ & 54 & 93.8 \\
17 & $\mathbf{1 9}$ & $\mathrm{H}$ & $\mathrm{OH}$ & $\mathrm{H}$ & $\mathrm{CF}_{3}$ & $\mathrm{Cl}$ & 86 & 94.5 \\
18 & $\mathbf{2 0}$ & $\mathrm{Cl}$ & $\mathrm{OH}$ & $\mathrm{H}$ & $\mathrm{CF}_{3}$ & $\mathrm{Cl}$ & 79 & 98.4 \\
19 & $\mathbf{2 1}$ & $\mathrm{H}$ & $\mathrm{OH}$ & $\mathrm{H}$ & $\mathrm{CF}_{3}$ & $\mathrm{Br}$ & 62 & 97.7 \\
20 & $\mathbf{2 2}$ & $\mathrm{Cl}$ & $\mathrm{OH}$ & $\mathrm{H}$ & $\mathrm{CF}_{3}$ & $\mathrm{Br}$ & 68 & $>99$ \\
21 & $\mathbf{2 3}$ & $\mathrm{Cl}$ & $\mathrm{OH}$ & $\mathrm{H}$ & $\mathrm{CF}_{3}$ & $\mathrm{H}$ & 80 & 96.5 \\
22 & $\mathbf{2 4}$ & $\mathrm{Cl}$ & $\mathrm{OH}$ & $\mathrm{H}$ & $\mathrm{H}$ & $\mathrm{Cl}$ & 81 & $>99$ \\
23 & $\mathbf{2 5}$ & $\mathrm{Cl}$ & $\mathrm{OH}$ & $\mathrm{H}$ & $\mathrm{H}$ & $\mathrm{Br}$ & 87 & 97.6 \\
\hline & & & & & & & &
\end{tabular}

As the next step, 20, 22, 24, and 25 were taken further to test activity against clinical drug-resistant $S$. aureus isolates along with levofloxacin, meropenem, and vancomycin as comparators. The MIC against clinical drugresistant $S$. aureus isolates is listed in Table 3. Since MDR $S$. aureus are a global threat to human health, it is an urgent unmet need to develop potential drug candidates for the treatment of MDR $S$. aureus infections. As can be seen in Table 3, compounds were tested against nine MRSA strains (NRS 10100, 10119, 10129, 10186, 10191-10194, and 10198) and three VRSA (VRS 1, 4, and 12). As shown in Table 3, 20, 24, and 25 inhibited MRSA and VRSA with MICs $0.25-0.5 \mu \mathrm{g} / \mathrm{mL}$. As expected, 22 found to be the most potent molecule inhibiting all MDR $S$. aureus isolates with MIC $0.031-0.062 \mu \mathrm{g} / \mathrm{mL}$, which is significantly better active than that of vancomycin (Table 3).

\section{2 exhibits concentration-dependent bactericidal activity}

Finally, comparative time-kill kinetics was assessed for $\mathbf{2 2}$ along with vancomycin as a comparator to determine whether it exhibits bactericidal activity (Fig. 2). The experiment was conducted for $24 \mathrm{~h}$ by adding $1 \times$ and $10 \times$
MIC of 22 and vancomycin, aliquots of cultures were removed, plated at 1,6 , and $24 \mathrm{~h}$ and the cfu are plotted in Fig. 2. As can be seen at $24 \mathrm{~h}, 10 \times$ MIC of 22 lead to $\sim 8$ $\log _{10} \mathrm{cfu} / \mathrm{mL}$ reduction, whereas $10 \times$ MIC of vancomycin reduced $\sim 9 \log _{10} \mathrm{cfu} / \mathrm{mL}$ with no regrowth (Fig. 2). Thus, 22 exhibits concentration-dependent bactericidal activity, which is comparable to vancomycin.

\section{2 significantly reduces pre-formed S. aureus biofilm}

The formation of biofilm is a self-protection phenotype of bacteria, which often leads to prolonged therapeutic intervention and increasing drug resistance. The effect of 22 on in vitro pre-formed biofilm was tested [21]. Figure 3 represents the bacterial biofilm inhibition activity of $\mathbf{2 2}$ and comparator drugs. As can be seen, treatment with $10 \times \mathrm{MIC}$ of 22 leads to a more significant reduction $(P<0.0005)$ in pre-formed biofilm as compared to either of comparators $(P$ $<0.05)$. Thus, 22 is able to exert its effect against bacteria in different growth phases, whereas vancomycin is not.

\section{2 does not interact with any FDA-approved drug}

Treatment of MDR infections typically requires a combination of drugs to achieve therapeutic clearance; thus, it 
Table 2 Minimum inhibitory concentration (MIC) $(\mu \mathrm{g} / \mathrm{mL})$ of salicylanilide derivatives against bacterial pathogen panel and cytotoxicity against Vero cells

\begin{tabular}{|c|c|c|c|c|c|c|c|}
\hline \multirow[t]{2}{*}{ Compound code } & \multicolumn{7}{|c|}{ MIC against bacterial pathogens $(\mu \mathrm{g} / \mathrm{mL})$} \\
\hline & $\begin{array}{l}\text { E. coli } \\
\text { ATCC } 25922\end{array}$ & $\begin{array}{l}\text { S. aureus } \\
\text { ATCC } 29213\end{array}$ & $\begin{array}{l}\text { K. pneumoniae } \\
\text { BAA } 1705\end{array}$ & $\begin{array}{l}\text { A. baumannii } \\
\text { BAA } 1605\end{array}$ & $\begin{array}{l}P . \text { aeruginosa } \\
\text { ATCC } 27853\end{array}$ & $\begin{array}{l}\text { Cytotoxicity against } \\
\text { Vero cells }\left(\mathrm{CC}_{50} \text {, }\right. \\
\mu \mathrm{g} / \mathrm{mL})\end{array}$ & $\begin{array}{l}\text { Selectivity index } \\
\text { with respect to } S \text {. } \\
\text { aureus ATCC } \\
29213 \text { (SI) }\end{array}$ \\
\hline 3 & $>64$ & $>64$ & $>64$ & $>64$ & $>64$ & nd & nd \\
\hline 4 & $>64$ & $>64$ & $>64$ & $>64$ & $>64$ & nd & nd \\
\hline 5 & $>64$ & 64 & $>64$ & $>64$ & $>64$ & nd & nd \\
\hline 6 & $>64$ & 8 & $>64$ & $>64$ & $>64$ & nd & nd \\
\hline 7 & $>64$ & 32 & $>64$ & $>64$ & $>64$ & nd & nd \\
\hline 8 & $>64$ & 2 & $>64$ & $>64$ & $>64$ & nd & nd \\
\hline 9 & $>64$ & 32 & $>64$ & $>64$ & $>64$ & nd & nd \\
\hline 10 & $>64$ & 4 & $>64$ & $>64$ & $>64$ & nd & nd \\
\hline 11 & $>64$ & 8 & $>64$ & $>64$ & $>64$ & nd & nd \\
\hline 12 & $>64$ & 0.5 & $>64$ & $>64$ & $>64$ & $<5$ & 9 \\
\hline 13 & $>64$ & 4 & $>64$ & $>64$ & $>64$ & nd & nd \\
\hline 14 & $>64$ & 0.5 & $>64$ & $>64$ & $>64$ & $<5$ & $<10$ \\
\hline 15 & $>64$ & 32 & $>64$ & $>64$ & $>64$ & nd & nd \\
\hline 16 & $>64$ & 4 & $>64$ & $>64$ & $>64$ & nd & nd \\
\hline 17 & $>64$ & 2 & $>64$ & $>64$ & $>64$ & nd & nd \\
\hline 18 & $>64$ & 1 & $>64$ & $>64$ & $>64$ & 5 & 5 \\
\hline 19 & $>64$ & 1 & $>64$ & $>64$ & $>64$ & $<10$ & $<10$ \\
\hline 20 & $>64$ & 0.25 & $>64$ & $>64$ & $>64$ & 5 & 20 \\
\hline 21 & $>64$ & 0.5 & $>64$ & $>64$ & $>64$ & $<5$ & $<10$ \\
\hline 22 & $>64$ & 0.25 & $>64$ & $>64$ & $>64$ & 5 & 20 \\
\hline 23 & $>64$ & 0.5 & $>64$ & $>64$ & $>64$ & $<5$ & $<10$ \\
\hline 24 & $>64$ & 0.5 & $>64$ & $>64$ & $>64$ & 20 & 40 \\
\hline 25 & $>64$ & 0.5 & $>64$ & $>64$ & $>64$ & 10 & 20 \\
\hline Levofloxacin & 0.0156 & 0.25 & 64 & 8 & 1 & $>100$ & $>400$ \\
\hline
\end{tabular}

nd $\mathrm{CC}_{50}$ not determined for compounds with $\mathrm{MIC}>1 \mu \mathrm{g} / \mathrm{mL}$

Compound codes and most active compounds MICs are represented in bold

is imperative to determine activity of drugs in combination with other approved FDA antibiotics. In this context, activity of $\mathbf{2 2}$ was determined in the presence of a panel of antibiotics that are clinically utilized for the treatment of staphylococcal infections. As shown in Table 4, 22 did not synergize with or antagonize any of FDA-approved antibiotic; thus, it can be utilized as a therapeutic combination.

\section{Structure-activity relationship}

The improved activity exhibited by salicylanilide than that of benzanilide indicated the importance of 2-hydroxyl group in benzoic acid (Fig. 4). 5-Chlorosalicylanilides demonstrated augment activity compared with salicylanilides in entire series. Activity was further improved eight-fold upon substitution of fluorine at 2'- or 4'-position in $\mathbf{1 2}$ and 14. 4'-Chloro or bromo-substituted compounds $\mathbf{2 4}$ and $\mathbf{2 5}$ maintain activity against $S$. aureus ATCC 29213. More interestingly, 3'-trifluoromethyl-substituted salicylanilides 2023 showed improved activity (MIC $0.25-0.5 \mu \mathrm{g} / \mathrm{mL}$ ).
Recently reported kinase inhibitor $N$-[3,5-Bis(trifluoromethyl)phenyl]-5-chloro-2-hydroxybenzamide (IMD0354) also exhibited similar activity (MIC $0.25 \mu \mathrm{g} /$ $\mathrm{mL}$ ) [24]. The SAR analysis of compounds 3-25 and IMD0354 suggested that 3'-trifluoromethyl group is crucial in order to improve activity. MDR $S$. aureus isolates inhibition activity of $\mathbf{2 0}, \mathbf{2 2}, \mathbf{2 4}$, and $\mathbf{2 5}$ identified 22 to be the most potent molecule inhibiting all MDR $S$. aureus isolates with MIC $0.031-0.062 \mu \mathrm{g} / \mathrm{mL}$. The results highlighted the importance of 3'-trifluoromethyl and 4'bromo substitution in expressing antimicrobial activity against MDR. S. aureus clinical isolates.

\section{Conclusions}

A series of novel fluoro and trifluoromethyl-substituted salicylanilide derivatives were synthesized and investigated for their MDR S. aureus inhibition activity. The in vitro cytotoxicity assay of compounds with $\mathrm{MIC}<1 \mu \mathrm{g} / \mathrm{mL}$ identified four compounds $(\mathbf{2 0}, \mathbf{2 2}, \mathbf{2 4}$, and 25) with SI $>10$. Remarkably, $\mathbf{2 2}$ bearing trifluoromethyl group demonstrates excellent 
Table 3 MIC $(\mu \mathrm{g} / \mathrm{mL})$ of salicylanilide derivatives against clinical MDR S. aureus isolates

\begin{tabular}{lllllllll}
\hline Drug-resistant strain & \multicolumn{7}{l}{ Compounds MIC $(\mu \mathrm{g} / \mathrm{mL})$} & \\
\cline { 2 - 9 } & 20 & 22 & 24 & 25 & Methicillin & Vancomycin & Levofloxacin & Meropenem \\
\hline MRSA & & & & & & & & \\
NRS 10100 & 0.5 & $\mathbf{0 . 0 6 2 5}$ & 0.5 & 0.5 & $>64$ & 2 & 0.25 & 64 \\
NRS 10119 & 0.5 & $\mathbf{0 . 0 3 1 2}$ & 0.25 & 0.25 & $>64$ & 2 & 16 & $>64$ \\
NRS 10129 & 0.5 & $\mathbf{0 . 0 6 2 5}$ & 0.5 & 0.5 & 32 & 1 & 0.25 & 16 \\
NRS 10186 & 0.5 & $\mathbf{0 . 0 6 2 5}$ & 0.5 & 0.5 & 64 & 1 & 8 & 16 \\
NRS 10191 & 0.5 & $\mathbf{0 . 0 6 2 5}$ & 0.5 & 0.5 & $>64$ & 2 & 16 & $>64$ \\
NRS 10192 & 0.5 & $\mathbf{0 . 0 3 1 2}$ & 0.5 & 0.5 & $>64$ & 2 & 8 & 32 \\
NRS 10193 & 0.5 & $\mathbf{0 . 0 6 2 5}$ & 0.5 & 0.5 & $>64$ & 2 & 32 & $>64$ \\
NRS 10194 & 0.5 & $\mathbf{0 . 0 6 2 5}$ & 0.5 & 0.5 & 32 & 1 & 0.125 & 4 \\
NRS 10198 & 0.5 & $\mathbf{0 . 0 6 2 5}$ & 0.5 & 0.5 & $>64$ & 2 & 32 & $>64$ \\
VRSA & & & & & & & & $>64$ \\
VRS 1 & 0.5 & $\mathbf{0 . 0 3 1 2}$ & 0.5 & 0.5 & $>64$ & $>64$ & 64 & $>64$ \\
VRS 4 & 0.25 & $\mathbf{0 . 0 6 2 5}$ & 0.5 & 0.5 & $>64$ & $>64$ & $>64$ & 16 \\
VRS 12 & 0.5 & $\mathbf{0 . 0 6 2 5}$ & 0.5 & 0.5 & $>64$ & $>64$ & 32 &
\end{tabular}

Compound codes and most active compounds MICs are represented in bold

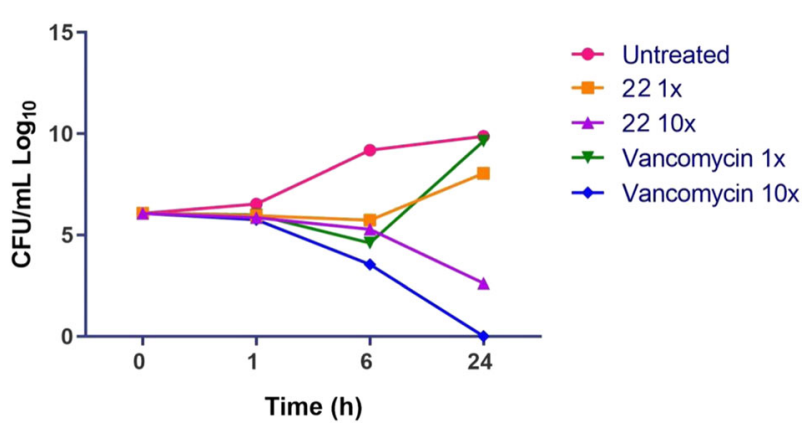

Fig. 2 Comparative time-kill kinetics of $\mathbf{2 2}$ and vancomycin against $S$. aureus ATCC 29213

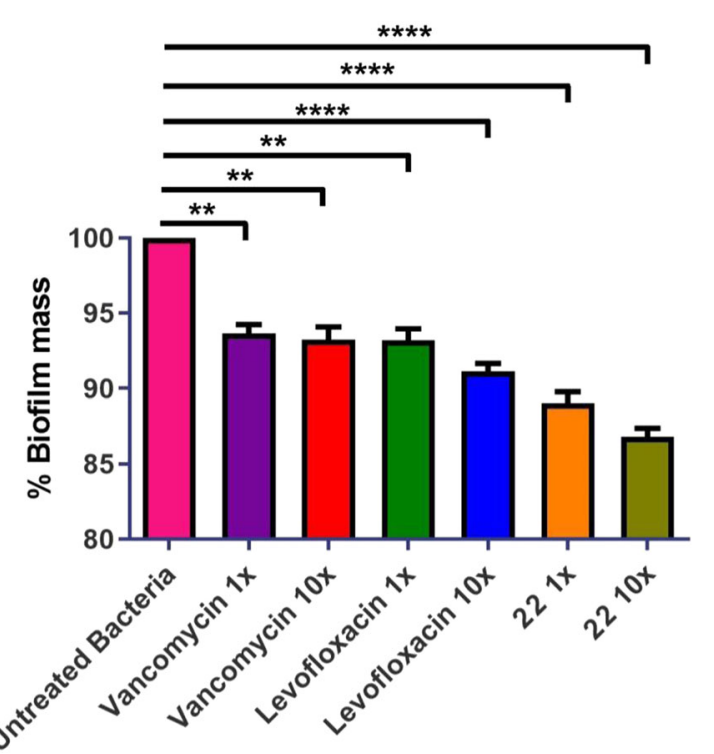

Fig. 3 Effects of 22 on S. aureus ATCC 29213 pre-formed biofilm and comparators. Three independent experiments were performed in triplicate. Bar represents the standard deviation. $* * * P<0.001$ activity against nine MRSA and three VRSA bacterial strains with MIC $0.031-0.062 \mu \mathrm{g} / \mathrm{mL}$, which is significantly better than that of vancomycin. The comparative time-kill kinetic experiment revealed that the effect of bacterial killing of 22 is comparable with vancomycin. Interestingly, $\mathbf{2 2}$ could reduce the pre-formed biofilm better than vancomycin and no drug interaction of $\mathbf{2 2}$ was observed in all tested drug combination. Thus, 22 fulfills all criteria to be further developed as a potent anti-staphylococcal therapeutic.

\section{Experimental section}

\section{General information}

Reactions were performed in oven-dried glassware apparatus and magnetic stir bars were used to make homogeneous solution. 5-Chlorosalicylic acid and aniline derivatives were procured from Sigma-Aldrich. Thin layer chromatography (TLC) was used to monitor reaction progress, which was carried out on Merck silica-gel plates $(0.25 \mathrm{~mm}$ thick, 60F254), and visualized by using UV (254 nm) or ninhydrin. ${ }^{1} \mathrm{H},{ }^{13} \mathrm{C},{ }^{19} \mathrm{~F}, \mathrm{COSY}, \mathrm{HSQC}$, and HMBC NMR spectra were measured on a Bruker $400 \mathrm{MHz}$ NMR instrument and processed using TopSpin 3.6.1. Chemical shifts $(\delta)$ are represented in parts per million (ppm) from the residual of nondeuterated solvents that is used as an internal standard ( ${ }^{1} \mathrm{H} \quad \mathrm{NMR}: \quad \mathrm{TMS} \quad \delta=0.00 \mathrm{ppm}, \mathrm{CDCl}_{3} \delta=7.26 \mathrm{ppm}$, DMSO- $d 6 \delta=2.50 \mathrm{ppm},{ }^{13} \mathrm{C}$ NMR: TMS $\delta=0.00 \mathrm{ppm}$, $\mathrm{CDCl}_{3} \delta=77.16 \mathrm{ppm}, \mathrm{DMSO}-d_{6} \delta=39.52 \mathrm{ppm}$ ) and coupling constants $(J)$ are given in hertz $(\mathrm{Hz})$. The multiplicities were expressed using the following abbreviations: $\mathrm{s}=$ singlet; $\mathrm{d}=$ doublet; $\mathrm{t}=$ triplet; $\mathrm{q}=$ quartet; $\mathrm{p}=$ pentet; 
Table 4 Combination of $\mathbf{2 2}$ with FDA-approved antibiotics against S. aureus ATCC 29213

\begin{tabular}{|c|c|c|c|c|c|c|c|}
\hline Drug & $\begin{array}{l}\text { MIC } \\
(\mu \mathrm{g} / \mathrm{mL})\end{array}$ & $\begin{array}{l}\text { MIC of " } 22 \text { " in } \\
\text { the presence of } \\
\text { drug }(\mu \mathrm{g} / \mathrm{mL}) \\
\text { "A" }\end{array}$ & $\begin{array}{l}\text { MIC of drug in } \\
\text { the presence of } \\
\text { " } 22 "(\mu \mathrm{g} / \mathrm{mL}) \\
\text { "B" }\end{array}$ & FIC A & FIC B & $\begin{array}{l}\Sigma \text { FIC } \\
(\text { FIC A }+ \\
\text { FIC B) }\end{array}$ & Inference \\
\hline 22 & 0.5 & & & & & & \\
\hline Ceftazidime & 16 & 0.5 & 16 & 1 & 1 & 2 & No interaction \\
\hline Daptomycin & 1 & 0.5 & 1 & 1 & 1 & 2 & No interaction \\
\hline Gentamicin & 0.5 & 0.25 & 0.25 & 0.5 & 0.5 & 1 & No interaction \\
\hline Linezolid & 2 & 0.25 & 0.5 & 0.5 & 0.25 & 0.75 & No interaction \\
\hline Levofloxacin & 0.25 & 0.5 & 0.25 & 1 & 1 & 2 & No interaction \\
\hline Minocycline & 0.125 & 0.5 & 0.125 & 1 & 1 & 2 & No interaction \\
\hline Meropenem & 0.5 & 0.5 & 0.5 & 1 & 1 & 2 & No interaction \\
\hline Rifampicin & 0.0078 & 0.5 & 0.0078 & 1 & 1 & 2 & No interaction \\
\hline Vancomycin & 1 & 0.25 & 0.5 & 0.5 & 0.5 & 1 & No interaction \\
\hline
\end{tabular}

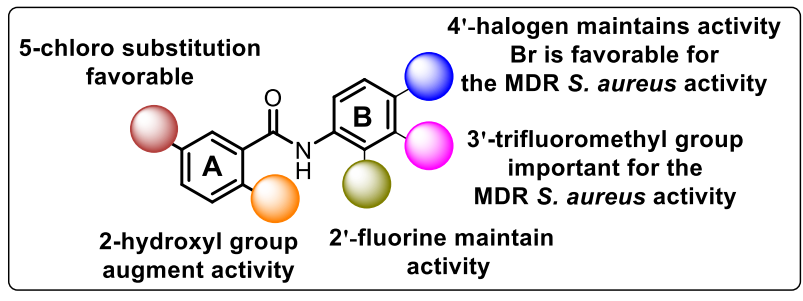

Fig. 4 SAR of synthesized salicylanilides

hept $=$ heptet; $\mathrm{dd}=$ doublet of doublets; $\mathrm{dt}=$ doublet of triplets; $\mathrm{td}=$ triplet of doublets; $\mathrm{bs}=$ broad singlet, $\mathrm{m}=$ multiplet. High-resolution mass spectra were obtained using Q-TOF mass spectrometer. Melting point was measured on Stuart SMP 10 melting point apparatus. Purity assessment was obtained on HPLC, carried out on analytical Agilent 1200 using ZORBAX Eclipse Plus $\mathrm{C}_{18}$ column ( $5 \mu \mathrm{m}, 4.6 \times$ $250 \mathrm{~mm}$, manufacturer: Agilent Technologies). The mobile phases used were $\mathrm{A}: \mathrm{H}_{2} \mathrm{O}$ with, $\mathrm{B}: \mathrm{CH}_{3} \mathrm{CN}$ using a solvent gradient $10-90 \%$ of A-B over 10 min with a flow rate of $1 \mathrm{~mL} / \mathrm{min}$, with detection at 220 and $254 \mathrm{~nm} \mathrm{UV}$ detectors.

\section{General procedure for the synthesis of compounds 3-25}

To a mixture of 5-chlorosalicylic acid (1a-d, $1 \mathrm{mmol})$ and aniline derivative (2a-k, $1 \mathrm{mmol})$ in a round bottom flask added $10 \mathrm{~mL}$ xylenes mixture (mixture of $\mathrm{o}-, \mathrm{m}-$, and $\mathrm{p}-$ xylenes) and heated to $120^{\circ} \mathrm{C}$ for $30 \mathrm{~min} . \mathrm{PCl}_{3}(0.4 \mathrm{mmol})$ was added dropwise for $5 \mathrm{~min}$, then the reaction contents stirred at $120^{\circ} \mathrm{C}$ for $3-4 \mathrm{~h}$. The reaction progress was monitored by TLC carried out on Merck silica-gel plates $(0.25 \mathrm{~mm}$ thick, $60 \mathrm{~F} 254)$ in ethylacetate-hexanes $(1: 3)$ and visualized by UV $(254 \mathrm{~nm})$ light. After complete consumption of starting materials (observed by TLC), the contents were brought to $70^{\circ} \mathrm{C}$, and then quenched with water. The resulting white precipitate was filtered and washed with water $\left(20 \mathrm{~mL}, 70^{\circ} \mathrm{C}\right)$, obtained desired salicylanilide with $>96 \%$ purity. Further washing with $10 \%$ ethanol in water $(20 \mathrm{~mL})$ removed trace amount $(3-4 \%)$ of unreacted aniline derivative. The wet white solid was dried under reduced pressure for 3-4h, resulted desired compounds (3-25) with $>98 \%$ purity.

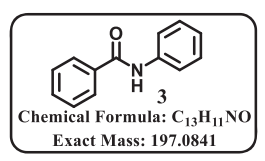

\section{$N$-phenylbenzamide (3)}

White solid, $73 \%$ yield, m.p. $159-162{ }^{\circ} \mathrm{C}$. IR (neat) $\nu_{\max }$ $\left(\mathrm{cm}^{-1}\right)$ : $3342(\mathrm{~N}-\mathrm{H}), 3047(\mathrm{C}-\mathrm{H}), 1653(\mathrm{C}=\mathrm{O}), 1523,1437$, $1075,751,689,648 .{ }^{1} \mathrm{H}$ NMR $\left(400 \mathrm{MHz}\right.$, DMSO- $\left.d_{6}\right) \delta$ 10.25 (s, 1H, NH), 7.97 (d, J=7.2 Hz, 2H, Ar-H), 7.80 (d, $J=7.9 \mathrm{~Hz}, 2 \mathrm{H}$, Ar-H), $7.57(\mathrm{~m}, 3 \mathrm{H}$, Ar-H), $7.36(\mathrm{t}, J=$ $7.7 \mathrm{~Hz}, 2 \mathrm{H}, \mathrm{Ar}-\mathrm{H}), 7.11(\mathrm{t}, J=7.2 \mathrm{~Hz}, 1 \mathrm{H}, \mathrm{Ar}-\mathrm{H}) .{ }^{13} \mathrm{C}$ NMR $\left(100 \mathrm{MHz}\right.$, DMSO- $\left.d_{6}\right) \delta 166.0(\mathrm{C}=\mathrm{O}), 139.6(\mathrm{NH}-$ C), 135.4 (Ar), 132.0 (Ar), 129.0 (2C, Ar), 128.8 (2C, Ar), 128.1 (2C, Ar), 124.1 (Ar), 120.8 (2C, Ar). HRMS: m/z [M-H] $]^{-}$calcd. for $\mathrm{C}_{13} \mathrm{H}_{10} \mathrm{NO}$ : 196.0763; found: 196.0765 .

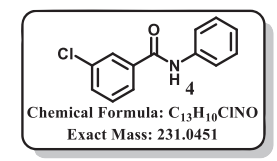

\section{$N$-(phenyl)-3-chlorobenzamide (4)}

White solid, $89 \%$ yield, m.p. $135-138^{\circ} \mathrm{C}$. IR (neat) $\nu_{\max }$ $\left(\mathrm{cm}^{-1}\right)$ : $3339(\mathrm{~N}-\mathrm{H}), 3055(\mathrm{C}-\mathrm{H}), 2922,1654(\mathrm{C}=\mathrm{O})$, 
1523, 1438, 1078, 744, 681, 654. ${ }^{1} \mathrm{H}$ NMR (400 MHz, DMSO- $\left.d_{6}\right) \delta$ in ppm: $10.35(\mathrm{~s}, 1 \mathrm{H}, \mathrm{NH}), 8.02(\mathrm{t}, J=$ 1.7 Hz, 1H, Ar-H), 7.93 (d, $J=7.7 \mathrm{~Hz}, 1 \mathrm{H}$, Ar-H), 7.78 (d, $J=7.9 \mathrm{~Hz}, 2 \mathrm{H}, \mathrm{Ar}-\mathrm{H}), 7.67$ (q, $J=3.0 \mathrm{~Hz}, 1 \mathrm{H}, \mathrm{Ar}-\mathrm{H})$, $7.57(\mathrm{t}, J=7.9 \mathrm{~Hz}, 1 \mathrm{H}, \mathrm{Ar}-\mathrm{H}), 7.37(\mathrm{t}, J=7.9 \mathrm{~Hz}, 2 \mathrm{H}$, Ar-H), $7.13(\mathrm{t}, \quad J=7.4 \mathrm{~Hz}, \quad 1 \mathrm{H}, \quad \mathrm{Ar}-\mathrm{H}) .{ }^{13} \mathrm{C} \quad \mathrm{NMR}$ $\left(100 \mathrm{MHz}, \mathrm{DMSO}-d_{6}\right) \delta 164.5(\underline{\mathrm{C}}=\mathrm{O}), 139.3$ (Ar), 137.3 (Ar), 133.6 (Ar), 131.8 (Ar), 130.8 (Ar), 129.1 (Ar), 127.8 (2C, Ar), 126.9 (Ar), 124.3 (Ar), 120.9 (2C, Ar). HRMS: $\mathrm{m} / \mathrm{z}[\mathrm{M}-\mathrm{H}]^{-}$calcd. for $\mathrm{C}_{13} \mathrm{H}_{9} \mathrm{ClNO}$ : 230.0373; found: 230.0377 .

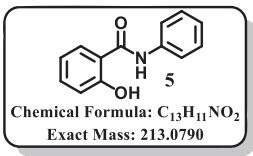

\section{$N$-(phenyl)-2-hydroxybenzamide (5)}

White solid, $83 \%$ yield, m.p. $128-132{ }^{\circ} \mathrm{C}$. IR (neat) $\nu_{\max }$ $\left(\mathrm{cm}^{-1}\right)$ : $3311(\mathrm{O}-\mathrm{H}), 3058(\mathrm{C}-\mathrm{H}), 2930(\mathrm{C}-\mathrm{H}), 1628(\mathrm{C}=\mathrm{O})$, 1544, 1368, 1235, 1451, 750, 689. ${ }^{1} \mathrm{H}$ NMR (400 MHz, DMSO- $\left.d_{6}\right) \delta$ in ppm: $11.83(\mathrm{~s}, 1 \mathrm{H}, \mathrm{OH}), 10.39$ (s, 1H, NH), 7.98 (d, $J=7.5 \mathrm{~Hz}, 1 \mathrm{H}, \mathrm{Ar}-\mathrm{H}), 7.72$ (d, $J=7.8 \mathrm{~Hz}, 2 \mathrm{H}, \mathrm{Ar}-$ $\mathrm{H}), 7.41(\mathrm{~m}, 3 \mathrm{H}, \mathrm{Ar}-\mathrm{H}), 7.15$ (t, $J=7.2 \mathrm{~Hz}, 1 \mathrm{H}, \mathrm{Ar}-\mathrm{H}), 6.98$ $(\mathrm{m}, 2 \mathrm{H}, \mathrm{Ar}-\mathrm{H}) .{ }^{13} \mathrm{C}$ NMR $\left(100 \mathrm{MHz}, \mathrm{DMSO}-d_{6}\right) \delta$ in ppm: $167.0(\mathrm{C}=\mathrm{O}), 158.9$ (C-OH), 138.6 (Ar), 134.1 (Ar), 129.5 (Ar), 129.2 (2C, Ar), 124.6 (Ar), 121.4 (2C, Ar), 119.5 (Ar), 117.9 (Ar), 117.7 (Ar); HRMS: m/z [M-H] ${ }^{-}$calcd. for $\mathrm{C}_{13} \mathrm{H}_{10} \mathrm{NO}_{2}$ : 212.0712; found: 212.0714 .

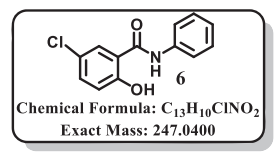

\section{5-Chloro- $N$-(phenyl)-2-hydroxy-benzamide (6)}

White solid, $84 \%$ yield, m.p. $203-205^{\circ} \mathrm{C}$. IR (neat) $\nu_{\max }$ $\left(\mathrm{cm}^{-1}\right)$ : $3401(\mathrm{O}-\mathrm{H}), 3314(\mathrm{~N}-\mathrm{H}), 2923(\mathrm{C}-\mathrm{H}), 1618(\mathrm{C}=\mathrm{O})$, 1221, 899, 817, 751, 697. ${ }^{1} \mathrm{H}$ NMR (400 MHz, DMSO-d ${ }_{6}$ ) $\delta$ in ppm: $11.87(\mathrm{~s}, 1 \mathrm{H}, \mathrm{OH}), 10.41(\mathrm{~s}, 1 \mathrm{H}, \mathrm{NH}), 7.98(\mathrm{~d}, J$ $=2.2 \mathrm{~Hz}, 1 \mathrm{H}, \mathrm{Ar}-\mathrm{H}), 7.71(\mathrm{~d}, J=7.9 \mathrm{~Hz}, 2 \mathrm{H}, \mathrm{Ar}-\mathrm{H}), 7.47$ $(\mathrm{dd}, J=2.3,8.7 \mathrm{~Hz}, 1 \mathrm{H}, \mathrm{Ar}-\mathrm{H}), 7.38(\mathrm{t}, J=7.7 \mathrm{~Hz}, 2 \mathrm{H}, \mathrm{Ar}-$ $\mathrm{H}), 7.15$ (t, $J=7.3 \mathrm{~Hz}, 1 \mathrm{H}, \mathrm{Ar}-\mathrm{H}), 7.02(\mathrm{~d}, J=8.8 \mathrm{~Hz}, 1 \mathrm{H}$, Ar-H). ${ }^{13} \mathrm{C}$ NMR $\left(100 \mathrm{MHz}, \mathrm{DMSO}-d_{6}\right) \delta$ in ppm: 165.4 $(\mathrm{C}=\mathrm{O}), 157.3$ (C-OH), 138.4 (Ar), 133.5 (Ar), 129.2 (2C), 128.8 (Ar), 124.8 (Ar), 123.2 (Ar), 121.3 (2C), 119.9 (Ar),
119.5 (Ar); HRMS: m/z [M-H] $]^{-}$calcd. for $\mathrm{C}_{13} \mathrm{H}_{9} \mathrm{CINO}_{2}$ : 246.0322; found: 246.0324 .

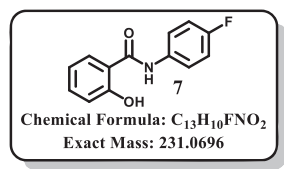

$N$-(4'-fluorophenyl)-2-hydroxybenzamide (7)

White solid, $60 \%$ yield, m.p. $157-161^{\circ} \mathrm{C}$. IR (neat) $\nu_{\max }$ $\left(\mathrm{cm}^{-1}\right)$ : $3411(\mathrm{O}-\mathrm{H}), 3300(\mathrm{~N}-\mathrm{H}), 2922(\mathrm{C}-\mathrm{H}), 1617(\mathrm{C}=\mathrm{O})$, $1564,1224,831,754,683 .{ }^{1} \mathrm{H}$ NMR $\left(400 \mathrm{MHz}, \mathrm{DMSO}-d_{6}\right)$ $\delta$ in ppm: $11.83(\mathrm{~s}, 1 \mathrm{H}, \mathrm{OH}), 10.42(\mathrm{~s}, 1 \mathrm{H}, \mathrm{NH}), 7.95(\mathrm{~d}, J$ $=7.5 \mathrm{~Hz}, 1 \mathrm{H}, \mathrm{Ar}-\mathrm{H}), 7.72$ (q, $J=4.5 \mathrm{~Hz}, 2 \mathrm{H}, \mathrm{Ar}-\mathrm{H}), 7.44$ $(\mathrm{t}, J=7.3 \mathrm{~Hz}, 1 \mathrm{H}, \mathrm{Ar}-\mathrm{H}), 7.21(\mathrm{t}, J=8.7 \mathrm{~Hz}, 2 \mathrm{H}, \mathrm{Ar}-\mathrm{H})$, $6.97(\mathrm{~m}, 2 \mathrm{H}, \mathrm{Ar}-\mathrm{H}) .{ }^{13} \mathrm{C}$ NMR $\left(100 \mathrm{MHz}, \mathrm{DMSO}-d_{6}\right) \delta$ in ppm: $167.1(\mathrm{C}=\mathrm{O}), 159.1$ (d, $J=240.3 \mathrm{~Hz}, \underline{\mathrm{C}}-\mathrm{F}), 159.0$ (드$\mathrm{OH}), 134.8(\mathrm{~d}, J=2.2 \mathrm{~Hz}, \mathrm{C}-\mathrm{C}=\mathrm{C}-\mathrm{F}), 134.1$ (Ar), 129.3 (Ar), 123.5 (Ar), 123.4 (d, J = 8.0 Hz, C-C=C-F), 119.5 (Ar), 117.8 (Ar), 117.7 (Ar), 115.9 (Ar), 115.7 (d, $J=$ $22.3 \mathrm{~Hz}, \underline{\mathrm{C}}=\mathrm{C}-\mathrm{F}) .{ }^{19} \mathrm{~F}$ NMR $\left(376 \mathrm{MHz}, \mathrm{DMSO}-d_{6}\right) \delta$ in ppm: -118.1 (s, 1F, Ar-F); HRMS: $\mathrm{m} / \mathrm{z}[\mathrm{M}+\mathrm{H}]^{+}$calcd. for $\mathrm{C}_{13} \mathrm{H}_{11} \mathrm{FNO}_{2}$ : 232.0774; found: 232.0767.

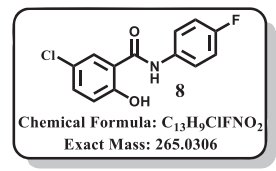

\section{5-Chloro- $N$-(4'-fluorophenyl)-2-hydroxybenzamide (8)}

White solid, $66 \%$ yield, m.p. $237-241^{\circ} \mathrm{C}$. IR (neat) $\nu_{\max }$ $\left(\mathrm{cm}^{-1}\right): 3404(\mathrm{O}-\mathrm{H}, \mathrm{N}-\mathrm{H}), 2920(\mathrm{C}-\mathrm{H}), 1624(\mathrm{C}=\mathrm{O}), 1382$, 1220, 1068, 820, 770, 658. ${ }^{1} \mathrm{H}$ NMR (400 MHz, DMSO- $\left.d_{6}\right)$ $\delta$ in ppm: $11.88(\mathrm{~s}, 1 \mathrm{H}, \mathrm{OH}), 10.43(\mathrm{~s}, 1 \mathrm{H}, \mathrm{NH}), 7.95(\mathrm{~d}, J$ $=2.5 \mathrm{~Hz}, 1 \mathrm{H}), 7.71(\mathrm{~m}, 2 \mathrm{H}), 7.46(\mathrm{~m}, 1 \mathrm{H}), 7.20(\mathrm{t}, J=$ $8.8 \mathrm{~Hz}, 2 \mathrm{H}), 7.00(\mathrm{~m}, 1 \mathrm{H}) .{ }^{13} \mathrm{C}$ NMR $\left(100 \mathrm{MHz}, \mathrm{DMSO}-d_{6}\right)$ $\delta$ in ppm: $170.2(\underline{\mathrm{C}}=\mathrm{O}), 163.9(\mathrm{~d}, J=241.3 \mathrm{~Hz}, \underline{\mathrm{C}}-\mathrm{F})$, 162.1 ( $\mathrm{C}-\mathrm{OH}), 139 . \overline{4}$ (Ar), 138.3 (Ar), 133.4 (Ar), 128.0 (d, $J=7.9 \mathrm{~Hz}, \underline{\mathrm{C}}-\mathrm{C}=\mathrm{C}-\mathrm{F}), 127.9$ (Ar), 124.4 (Ar), $124.2(\mathrm{Ar})$, $120.5(\mathrm{~d}, \bar{J}=22.3 \mathrm{~Hz}, \quad \mathrm{C}=\mathrm{C}-\mathrm{F}) .{ }^{19} \mathrm{~F} \quad \mathrm{NMR} \quad(376 \mathrm{MHz}$, DMSO- $\left.d_{6}\right) \delta$ in ppm: $-113.1(\mathrm{~s}, 1 \mathrm{~F}) ; \mathrm{HRMS}: \mathrm{m} / \mathrm{z}[\mathrm{M}+\mathrm{H}]^{+}$ calcd. for $\mathrm{C}_{13} \mathrm{H}_{10} \mathrm{ClFNO}_{2}$ : 266.0384; found: 266.0374 .

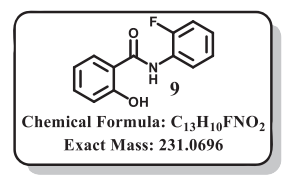




\section{$N$-(2'-fluorophenyl)-2-hydroxybenzamide (9)}

White solid, $69 \%$ yield, m.p. $138-141^{\circ} \mathrm{C}$. IR (neat) $\nu_{\max }$ $\left(\mathrm{cm}^{-1}\right): 3282(\mathrm{O}-\mathrm{H}, \mathrm{N}-\mathrm{H}), 3063(\mathrm{C}-\mathrm{H}), 2935(\mathrm{C}-\mathrm{H}), 1613$ $(\mathrm{C}=\mathrm{O}), 1551,1233,749,713,689 .{ }^{1} \mathrm{H} \mathrm{NMR}(400 \mathrm{MHz}$, DMSO- $\left.d_{6}\right) \delta$ in ppm: $11.97(\mathrm{~s}, 1 \mathrm{H}, \mathrm{OH}), 10.70(\mathrm{~s}, 1 \mathrm{H}, \mathrm{NH})$, $8.20(\mathrm{~m}, 1 \mathrm{H}, \mathrm{Ar}-\mathrm{H}), 8.03$ (dd, $J=7.9,1.6 \mathrm{~Hz}, 1 \mathrm{H}, \mathrm{Ar}-\mathrm{H})$, 7.46 (m, 1H, Ar-H), 7.32 (m, 1H, Ar-H), 7.22 (m, 2H, Ar$\mathrm{H}), 7.01$ (m, 2H, Ar-H). ${ }^{13} \mathrm{C} \mathrm{NMR}\left(100 \mathrm{MHz}, \mathrm{DMSO}-d_{6}\right) \delta$ in ppm: $165.1(\mathrm{C}=\mathrm{O}), 157.5(\underline{\mathrm{C}}-\mathrm{OH}), 153.8(\mathrm{~d}, J=$ $243.5 \mathrm{~Hz}, \underline{\mathrm{C}}-\mathrm{F}), 134.4$ (Ar), 130.7 (Ar), 126.5 (d, $J=$ $10.6 \mathrm{~Hz}, \mathrm{C}=\mathrm{C}-\mathrm{F}), 125.7(\mathrm{~d}, J=7.6 \mathrm{~Hz}, \mathrm{C}-\mathrm{C}=\mathrm{C}-\mathrm{F}), 125.1$ (d, $J=3.1 \mathrm{~Hz}, \underline{\mathrm{C}}-\mathrm{C}=\mathrm{C}-\mathrm{F}), 123.8$ (Ar), 120.1 (Ar), 118.0 (Ar), 117.5 (Ar), 115.7 (d, $J=19.2 \mathrm{~Hz}, \underline{\mathrm{C}}=\mathrm{C}-\mathrm{F}) .{ }^{19} \mathrm{~F}$ NMR $\left(376 \mathrm{MHz}, \mathrm{DMSO}-d_{6}\right) \delta$ in ppm: $-12 \overline{7} .2$ (s, 1F, Ar-F); HRMS: $\mathrm{m} / \mathrm{z}[\mathrm{M}+\mathrm{H}]^{+}$calcd. for $\mathrm{C}_{13} \mathrm{H}_{11} \mathrm{FNO}_{2}$ : 232.0774; found: 232.0765 .

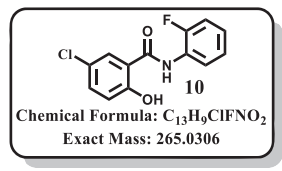

\section{5-Chloro- $N$-(2'-fluorophenyl)-2-hydroxybenzamide (10)}

White solid, $65 \%$ yield, m.p. $226-229^{\circ} \mathrm{C}$. IR (neat) $\nu_{\max }$ $\left(\mathrm{cm}^{-1}\right)$ : 3404 (O-H, N-H), $2923(\mathrm{C}-\mathrm{H}), 1609$ (C=O), 1545, 1384, 1073, 816, 744, 683. ${ }^{1} \mathrm{H}$ NMR (400 MHz, DMSO-d $\left.{ }_{6}\right)$ $\delta$ in ppm: $12.22(\mathrm{~s}, 1 \mathrm{H}, \mathrm{OH}), 10.68(\mathrm{~s}, 1 \mathrm{H}, \mathrm{NH}), 8.20(\mathrm{~m}$, 1H, Ar-H), 7.98 (d, $J=2.7 \mathrm{~Hz}, 1 \mathrm{H}, \mathrm{Ar}-\mathrm{H}), 7.50$ (dd, $J=$ 8.8, $2.8 \mathrm{~Hz}, 1 \mathrm{H}, \mathrm{Ar}-\mathrm{H}), 7.32(\mathrm{~m}, 1 \mathrm{H}, \mathrm{Ar}-\mathrm{H}), 7.23(\mathrm{~m}, 2 \mathrm{H}$, Ar-H), $7.06 \quad(\mathrm{~d}, \quad J=8.8 \mathrm{~Hz}, \quad 1 \mathrm{H}, \quad \mathrm{Ar}-\mathrm{H}) . \quad{ }^{13} \mathrm{C} \quad \mathrm{NMR}$ $\left(100 \mathrm{MHz}, \mathrm{DMSO}-d_{6}\right) \delta$ in ppm: $163.6(\mathrm{C}=\mathrm{O}), 156.2(\underline{\mathrm{C}}-$ $\mathrm{OH}$ ), 153.7 (d, $J=243.9 \mathrm{~Hz}, \underline{\mathrm{C}}-\mathrm{F}), 133.8$ (Ar), 129.8 (Ar), $126.3(\mathrm{~d}, J=10.7 \mathrm{~Hz}, \underline{\mathrm{C}}=\mathrm{C}-\mathrm{F}), 125.9$ (d, $J=7.7 \mathrm{~Hz}, \underline{\mathrm{C}}-$ $\mathrm{C}=\mathrm{C}-\mathrm{F}), 125.1 \quad(\mathrm{~d}, J=3.3 \mathrm{~Hz}, \quad \mathrm{C}-\mathrm{C}=\mathrm{C}-\mathrm{F}), 123.8 \quad(\mathrm{Ar})$, 123.6 (Ar), 119.8 (Ar), 119.5 (Ar), 115.7 (d, $J=19.2 \mathrm{~Hz}$, $\mathrm{C}=\mathrm{C}-\mathrm{F}) .{ }^{19} \mathrm{~F}$ NMR $\left(376 \mathrm{MHz}, \mathrm{DMSO}-d_{6}\right) \delta$ in ppm: -127.3 (s, 1F, Ar-F); HRMS: $\mathrm{m} / \mathrm{z}[\mathrm{M}+\mathrm{H}]^{+}$calcd. for $\mathrm{C}_{13} \mathrm{H}_{10} \mathrm{ClFNO}_{2}$ : 266.0384; found: 266.0374 .

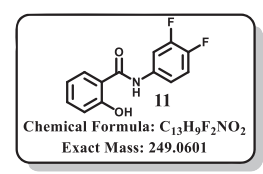

\section{$\mathrm{N}$-(3',4'-difluorophenyl)-2-hydroxybenzamide (11)}

White solid, $47 \%$ yield, m.p. $192-194{ }^{\circ} \mathrm{C}$. IR (neat) $\nu_{\max }$ $\left(\mathrm{cm}^{-1}\right)$ : 3379 (O-H, N-H), $2922(\mathrm{C}-\mathrm{H}), 1615(\mathrm{C}=\mathrm{O}), 1372$,
1221, 1109, 814, 765, 666. ${ }^{1} \mathrm{H}$ NMR (400 MHz, DMSO- $\left.d_{6}\right)$ $\delta$ in ppm: $11.61(\mathrm{~s}, 1 \mathrm{H}, \mathrm{OH}), 10.49(\mathrm{~s}, 1 \mathrm{H}, \mathrm{NH}), 7.89(\mathrm{~m}$, 2H, Ar-H), 7.42 (m, 3H, Ar-H), 6.97 (m, 2H, Ar-H). ${ }^{13} \mathrm{C}$ NMR (100 MHz, DMSO- $\left.d_{6}\right) \delta$ in ppm: $167.0(\underline{\mathrm{C}}=\mathrm{O}), 158.6$ (C-OH), 149.3 (dd, $J=243.6,13.3 \mathrm{~Hz}, \underline{\mathrm{C}}-\mathrm{F}), 146.2$ (dd, $J$ $=242.8,12.5 \mathrm{~Hz}, \underline{\mathrm{C}}-\mathrm{F}), 135.6(\mathrm{dd}, J=8.3,2.9, \mathrm{~Hz}, \underline{\mathrm{C}}-$ $\mathrm{C}=\mathrm{C}-\mathrm{F}), 134.19$ (Ar), 129.5 (Ar), 119.5 (Ar), 118.0 (Ar), 117.8 (Ar), 117.6 (Ar), 117.5 (Ar), 110.3 (d, $J=21.5 \mathrm{~Hz}$, $\underline{\mathrm{C}}=\mathrm{C}-\mathrm{F}) .{ }^{19} \mathrm{~F}$ NMR $\left(376 \mathrm{MHz}, \mathrm{DMSO}-d_{6}\right) \delta$ in ppm: $-137.2(\mathrm{~d}, J=23.0 \mathrm{~Hz}, 1 \mathrm{~F}, \mathrm{Ar}-\mathrm{F}),-143.8(\mathrm{~d}, J=23.0 \mathrm{~Hz}$, 1F, Ar-F); HRMS: m/z $[\mathrm{M}+\mathrm{H}]^{+}$calcd. for $\mathrm{C}_{13} \mathrm{H}_{10} \mathrm{~F}_{2} \mathrm{NO}_{2}$ : 250.0681; found: 250.0677 .

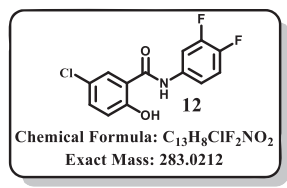

5-Chloro-N-(3',4'-difluorophenyl)-2-hydroxybenzamide (12)

White solid, $51 \%$ yield, m.p. $249-252{ }^{\circ} \mathrm{C}$. IR (neat) $\nu_{\max }$ $\left(\mathrm{cm}^{-1}\right)$ : $3402(\mathrm{O}-\mathrm{H}), 3308(\mathrm{~N}-\mathrm{H}), 2920(\mathrm{C}-\mathrm{H}), 1621(\mathrm{C}=\mathrm{O})$, 1556, 1277, 1208, 771, 685. ${ }^{1} \mathrm{H}$ NMR (400 MHz, DMSO$\left.d_{6}\right) \delta$ in ppm:10.49 (s, 1H, OH), $7.85(\mathrm{~m}, 2 \mathrm{H}, \mathrm{NH}), 7.40(\mathrm{~m}$, $3 \mathrm{H}, \mathrm{Ar}-\mathrm{H}), 7.00(\mathrm{~d}, J=8.8 \mathrm{~Hz}, 1 \mathrm{H}, \mathrm{Ar}-\mathrm{H}) .{ }^{13} \mathrm{C} \mathrm{NMR}$ $\left(100 \mathrm{MHz}, \mathrm{DMSO}-d_{6}\right) \delta$ in ppm: $165.1(\underline{\mathrm{C}}=\mathrm{O}), 156.7(\underline{\mathrm{C}}-$ $\mathrm{OH}), 149.3(\mathrm{dd}, J=243.4,13.3 \mathrm{~Hz}, \mathrm{C}-\mathrm{F}), 146.3(\mathrm{dd}, J=$ $243.0,13.0 \mathrm{~Hz}, \underline{\mathrm{C}}-\mathrm{F}), 135.4$ (dd, $J=8.8,2.9 \mathrm{~Hz}, \underline{\mathrm{C}}-\mathrm{C}=\mathrm{C}-$ F), 133.2 (Ar), 128.5 (Ar), 122.9 (Ar), 119.6 (Ar), 119.1 (Ar), $117.7(\mathrm{~d}, J=17.6 \mathrm{~Hz}, \underline{\mathrm{C}}=\mathrm{C}-\mathrm{F}), 117.4(\mathrm{dd}, J=6.6$, $3.6 \mathrm{~Hz}, \underline{\mathrm{C}}-\mathrm{C}=\mathrm{C}-\mathrm{F}), 110.2(\mathrm{~d}, J=21.3, \mathrm{~Hz}, \underline{\mathrm{C}}=\mathrm{C}-\mathrm{F}) .{ }^{19} \mathrm{~F}$ NMR $\left(376 \mathrm{MHz}\right.$, DMSO- $\left.d_{6}\right) \delta$ in ppm: -137.1 (d, $J=$ $22.9 \mathrm{~Hz}, 1 \mathrm{~F}, \mathrm{Ar}-\mathrm{F}),-143.5(\mathrm{~d}, J=23.0 \mathrm{~Hz}, 1 \mathrm{~F}, \mathrm{Ar}-\mathrm{F})$; HRMS m/z Calcd for $[\mathrm{M}+\mathrm{H}]^{+} \mathrm{C}_{13} \mathrm{H}_{9} \mathrm{ClF}_{2} \mathrm{NO}_{2}$ is 284.0290, found 284.0293 .

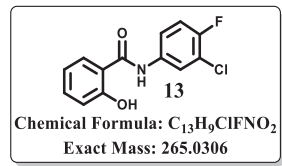

$N$-(3'-chloro-4'-fluorophenyl)-2-hydroxybenzamide (13)

White solid, $96 \%$ yield, m.p. $203-205^{\circ} \mathrm{C}$. IR (neat) $\nu_{\max }$ $\left(\mathrm{cm}^{-1}\right)$ : $3409(\mathrm{O}-\mathrm{H}), 3324(\mathrm{~N}-\mathrm{H}), 2920(\mathrm{C}-\mathrm{H}), 1623(\mathrm{C}=\mathrm{O})$, 1385, 1231, 803, 740. ${ }^{1} \mathrm{H}$ NMR (400 MHz, DMSO- $\left.d_{6}\right) \delta$ in ppm: 11.55 (s, 1H, OH), 10.48 (s, 1H, NH), 8.30 (s,1H, ArH), 8.05 (dd, $J=6.9,2.6 \mathrm{~Hz}, 1 \mathrm{H}, \mathrm{Ar}-\mathrm{H}), 7.90$ (dd, $J=7.9$, 
$1.6 \mathrm{~Hz}, 1 \mathrm{H}, \mathrm{Ar}-\mathrm{H}), 7.66$ (m, 1H, Ar-H), 7.49-7.39 (m, 2H, Ar-H), 7.04-6.92 (m, 2H, Ar-H). ${ }^{13} \mathrm{C}$ NMR $(100 \mathrm{MHz}$, DMSO- $\left.d_{6}\right) \delta$ in ppm: $167.1(\underline{\mathrm{C}}=\mathrm{O}), 158.8(\underline{\mathrm{C}}-\mathrm{OH}), 154.1$ (d, $J=243.8 \mathrm{~Hz}, \underline{\mathrm{C}}-\mathrm{F}), 135.9(\mathrm{~d}, J=3.1 \mathrm{~Hz}, \underline{\mathrm{C}}-\mathrm{C}=\mathrm{C}-\mathrm{F})$, 134.2 (Ar), 129.5 (Ar), 122.8 (Ar), 121.6 (d, $J=6.8 \mathrm{~Hz}, \underline{\mathrm{C}}-$ $\mathrm{C}=\mathrm{C}-\mathrm{F}), 119.6(\mathrm{~d}, J=18.4 \mathrm{~Hz}, \mathrm{C}=\mathrm{C}-\mathrm{F}), 119.4(\mathrm{Ar}), 117.8$ (Ar), 117.6 (Ar), 117.1 (d, $J=21.8 \mathrm{~Hz}, \underline{\mathrm{C}}=\mathrm{C}-\mathrm{F}) .{ }^{19} \mathrm{~F}$ NMR $\left(376 \mathrm{MHz}, \mathrm{DMSO}-d_{6}\right) \delta$ in ppm: -121.8 (s, 1F, Ar-F). HRMS m/z Calcd for $[\mathrm{M}+\mathrm{H}]^{+} \mathrm{C}_{13} \mathrm{H}_{10} \mathrm{ClFNO}_{2}$ is 266.0384, found 266.0387 .

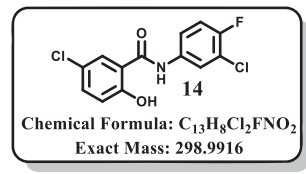

\section{5-Chloro-N-(3'-chloro-4'-fluorophenyl)-2-hydroxybenzamide} (14)

White solid, $75 \%$ yield, m.p. $220-224^{\circ} \mathrm{C}$. IR (neat) $\nu_{\max }$ $\left(\mathrm{cm}^{-1}\right)$ : $3395(\mathrm{O}-\mathrm{H}), 3315(\mathrm{~N}-\mathrm{H}), 2924(\mathrm{C}-\mathrm{H}), 1627(\mathrm{C}=\mathrm{O})$, 1494, 1218, 872, 814, 668. ${ }^{1} \mathrm{H}$ NMR (400 MHz, DMSO- $d_{6}$ ) $\delta 11.65$ (s, 1H, OH), 10.50 (s, 1H, NH), 8.02 (dd, $J=6.8$, $2.5 \mathrm{~Hz}, 1 \mathrm{H}, \mathrm{Ar}-\mathrm{H}), 7.88$ (d, J=2.7 Hz, 1H, Ar-H), 7.64 (m, 1H), 7.44 (m, 2H, Ar-H), 7.02 (d, J=8.8 Hz, 1H, Ar-H). ${ }^{13} \mathrm{C}$ NMR $\left(100 \mathrm{MHz}, \mathrm{DMSO}-d_{6}\right) \delta$ in ppm: $167.1(\underline{\mathrm{C}}=\mathrm{O})$, 158.8 ( $\underline{\mathrm{C}}-\mathrm{OH}), 154.1$ (d, $J=243.8 \mathrm{~Hz}, \underline{\mathrm{C}}-\mathrm{F}), 135.9$ (d, $J=$ $3.1 \mathrm{~Hz}, \mathrm{C}-\mathrm{C}=\mathrm{C}-\mathrm{F}), 134.2$ (Ar), 129.5 (Ar), 122.8 (Ar), $121.6(\mathrm{~d}, J=6.8 \mathrm{~Hz}, \quad \underline{C}-\mathrm{C}=\mathrm{C}-\mathrm{F}), 119.6(\mathrm{~d}, J=18.4 \mathrm{~Hz}$, $\underline{\mathrm{C}}=\mathrm{C}-\mathrm{F}), 119.4$ (Ar), 117.8 (Ar), 117.6 (Ar), 117.1 (d, $J=$ $21.8 \mathrm{~Hz}, \underline{\mathrm{C}}=\mathrm{C}-\mathrm{F}) .{ }^{19} \mathrm{~F}$ NMR $\left(376 \mathrm{MHz}, \mathrm{DMSO}-d_{6}\right) \delta$ in ppm: -121.5 (s, 1F, Ar-F); HRMS: m/z [M-H] ${ }^{+}$calcd. For $\mathrm{C}_{13} \mathrm{H}_{7} \mathrm{Cl}_{2} \mathrm{FNO}_{2}$ : 297.9838; found: 297.9840 .

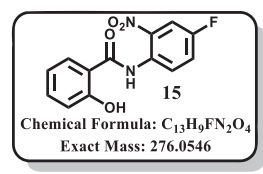

\section{$N$-(4'-fluoro-2'-nitrophenyl)-2-hydroxybenzamide (15)}

White solid, $62 \%$ yield, m.p. $160-163{ }^{\circ} \mathrm{C}$. IR (neat) $\nu_{\max }$ $\left(\mathrm{cm}^{-1}\right)$ : 3339 (O-H, N-H), $2922(\mathrm{C}-\mathrm{H}), 1644(\mathrm{C}=\mathrm{O}), 1509$, 1341, 1261, 828, 748, 656. ${ }^{1} \mathrm{H}$ NMR (400 MHz, DMSO- $d_{6}$ ) $\delta$ in ppm: $11.80(\mathrm{~s}, 1 \mathrm{H}, \mathrm{OH}), 11.72(\mathrm{~s}, 1 \mathrm{H}, \mathrm{NH}), 8.49(\mathrm{~m}$, 1H, Ar-H), 7.99 (m, 2H, Ar-H), 7.67 (m, 1H, Ar-H), 7.45 (t, $J=7.1 \mathrm{~Hz}, 1 \mathrm{H}, \mathrm{Ar}-\mathrm{H}), 7.00$ (m, 2H, Ar-H). ${ }^{13} \mathrm{C} \mathrm{NMR}$ $\left(100 \mathrm{MHz}, \mathrm{DMSO}-d_{6}\right) \delta$ in ppm: $165.2(\underline{\mathrm{C}}=\mathrm{O}), 157.5(\mathrm{~d}, J$ $=244.6 \mathrm{~Hz}, \underline{\mathrm{C}}-\mathrm{F}), 157.4$ ( $\underline{\mathrm{C}}-\mathrm{OH}), 140.3$ (d, J=8.5 Hz, $\underline{\mathrm{C}}-$
$\mathrm{C}=\mathrm{C}-\mathrm{F}), 134.6(\mathrm{Ar}), 131.1(\mathrm{Ar}), 130.0(\mathrm{Ar}), 126.9(\mathrm{~d}, J=$ $8.0 \mathrm{~Hz}, \underline{\mathrm{C}}-\mathrm{C}=\mathrm{C}-\mathrm{F}), 122.4(\mathrm{~d}, J=22.1 \mathrm{~Hz}, \underline{\mathrm{C}}=\mathrm{C}-\mathrm{F}), 120.0$ (Ar), 118.1 (Ar), 117.4 (Ar), 112.6 (d, $J=\overline{2} 7.4 \mathrm{~Hz}, \underline{\mathrm{C}}=\mathrm{C}-$ F). ${ }^{19} \mathrm{~F}$ NMR $\left(376 \mathrm{MHz}, \mathrm{DMSO}-d_{6}\right) \delta$ in ppm: $-11 \overline{6.0}(\mathrm{~s}$, 1F, Ar-F); HRMS: m/z $[\mathrm{M}+\mathrm{H}]^{+}$calcd. For $\mathrm{C}_{13} \mathrm{H}_{10} \mathrm{FN}_{2} \mathrm{O}_{4}$ : 277.0624; found: 277.0620 .

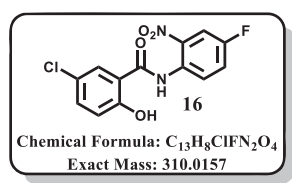

5-Chloro-N-(4'-fluoro-2'-nitrophenyl)-2-hydroxybenzamide (16)

White solid, $67 \%$ yield, m.p. $160-164{ }^{\circ} \mathrm{C}$. IR (neat) $\nu_{\max }$ $\left(\mathrm{cm}^{-1}\right): 3339$ (O-H, N-H), $3100(\mathrm{C}-\mathrm{H}), 2922(\mathrm{C}-\mathrm{H}), 1654$ $(\mathrm{C}=\mathrm{O}), 1513,1343,839,727,648 .{ }^{1} \mathrm{H} \mathrm{NMR}(400 \mathrm{MHz}$, DMSO- $\left.d_{6}\right) \delta$ in ppm: $12.10(\mathrm{~s}, 1 \mathrm{H}, \mathrm{OH}), 11.72(\mathrm{~s}, 1 \mathrm{H}, \mathrm{NH})$, 8.48 (m, 1H, Ar-H), 8.00 (m, 1H, Ar-H), 7.89 (m, 1H, ArH), 7.67 (m, 1H, Ar-H), 7.47 (m, 1H, Ar-H), $7.03(\mathrm{~m}, 1 \mathrm{H}$, Ar-H). ${ }^{13} \mathrm{C}$ NMR (100 MHz, DMSO- $\left.d_{6}\right) \delta$ in ppm: 163.7 $(\underline{\mathrm{C}}=\mathrm{O}), 158.4(\mathrm{~d}, J=245.5 \mathrm{~Hz}, \underline{\mathrm{C}}-\mathrm{F}), 156.1(\underline{\mathrm{C}}-\mathrm{OH}), 140.2$ $(\overline{\mathrm{d}}, J=8.7 \mathrm{~Hz}, \underline{\mathrm{C}}-\mathrm{C}=\mathrm{C}-\mathrm{F}), 134.1,130.2(\mathrm{Ar}), 129.8(\mathrm{Ar})$, $126.8(\mathrm{~d}, J=7.8 \mathrm{~Hz}, \underline{\mathrm{C}}-\mathrm{C}=\mathrm{C}-\mathrm{F}), 123.7(\mathrm{Ar}), 122.5(\mathrm{~d}, J=$ $22.1 \mathrm{~Hz}, \mathrm{C}=\mathrm{C}-\mathrm{F}), 119.7$ (Ar), $119.4(\mathrm{Ar}), 112.7(\mathrm{~d}, J=$ $27.5 \mathrm{~Hz}, \underline{\mathrm{C}}=\mathrm{C}-\mathrm{F}) .{ }^{19} \mathrm{~F}$ NMR $\left(376 \mathrm{MHz}, \mathrm{DMSO}-d_{6}\right) \delta$ in ppm: -115.8 (s, 1F, Ar-F); HRMS: m/z [M+H] ${ }^{+}$calcd. For $\mathrm{C}_{13} \mathrm{H}_{9} \mathrm{ClFN}_{2} \mathrm{O}_{4}$ : 311.0235; found: 311.0230.

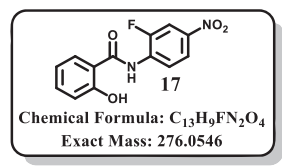

$N$-(2'-fluoro-4'-nitrophenyl)-2-hydroxybenzamide (17)

White solid, $53 \%$ yield, m.p. $238-241^{\circ} \mathrm{C}$. IR (neat) $\nu_{\max }$ $\left(\mathrm{cm}^{-1}\right): 3393$ (O-H, N-H), 3092 (C-H), 2923 (C-H), 1638 $(\mathrm{C}=\mathrm{O}), 1509,1226,886,741,680 .{ }^{1} \mathrm{H} \mathrm{NMR}(400 \mathrm{MHz}$, DMSO- $\left.d_{6}\right) \delta$ in ppm: $12.04(\mathrm{~s}, 1 \mathrm{H}, \mathrm{OH}), 11.17$ (s, 1H, NH), 8.71 (m, Hz, 1H, Ar-H), 8.22 (m, 1H, Ar-H), 8.17 (m, 1H, Ar-H), 8.03 (m, 1H, Ar-H), 7.49 (m, 1H, Ar-H), 7.04 (m, $2 \mathrm{H}, \mathrm{Ar}-\mathrm{H}) .{ }^{13} \mathrm{C}$ NMR $\left(100 \mathrm{MHz}, \mathrm{DMSO}-d_{6}\right) \delta$ in ppm: $164.5(\mathrm{C}=\mathrm{O}), 156.8(\mathrm{C}-\mathrm{OH}), 151.48(\mathrm{~d}, J=246.7 \mathrm{~Hz}, \mathrm{C}-$ F), $142 . \overline{6}(\mathrm{~d}, J=8.9 \mathrm{~Hz}, \mathrm{C}-\mathrm{C}=\mathrm{C}-\mathrm{F}), 134.9$ (Ar), $133.8(\overline{\mathrm{Ar}})$ $(\mathrm{d}, J=10.3 \mathrm{~Hz}, \underline{\mathrm{C}}=\mathrm{C}-\mathrm{F}), 131.4(\mathrm{Ar}), 121.5(\mathrm{~d}, J=3.0 \mathrm{~Hz}$, C-C =C-F), 121.1 (Ar), 120.5 (Ar), 118.3 (Ar), 117.5 (Ar), 
$111.6 \quad(\mathrm{~d}, \quad J=24.7 \mathrm{~Hz}, \quad \mathrm{C}=\mathrm{C}-\mathrm{F}) .{ }^{19} \mathrm{~F} \quad \mathrm{NMR} \quad(376 \mathrm{MHz}$, DMSO- $\left.d_{6}\right) \delta$ in ppm: -126.0 (s, $1 \mathrm{~F}$, Ar-F); HRMS: m/z $[\mathrm{M}-\mathrm{H}]^{-}$calcd. For $\mathrm{C}_{13} \mathrm{H}_{8} \mathrm{FN}_{2} \mathrm{O}_{4}$ : 275.0468; found: 275.0472 .

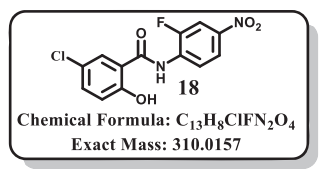

\section{5-Chloro- $N$-(2'-fluoro-4'-nitrophenyl)-2-hydroxybenzamide} (18)

White solid, $54 \%$ yield, m.p. $248-252{ }^{\circ} \mathrm{C}$. IR (neat) $\nu_{\max }$ $\left(\mathrm{cm}^{-1}\right)$ : $3394(\mathrm{O}-\mathrm{H}, \mathrm{N}-\mathrm{H}), 2922(\mathrm{C}-\mathrm{H}), 1613(\mathrm{C}=\mathrm{O}), 1495$, $1329,1065,885,818,774 .{ }^{1} \mathrm{H}$ NMR $\left(400 \mathrm{MHz}, \mathrm{DMSO}-d_{6}\right)$ $\delta$ in ppm: $12.45(\mathrm{~s}, 1 \mathrm{H}, \mathrm{OH}), 11.10(\mathrm{~s}, 1 \mathrm{H}, \mathrm{NH}), 8.66(\mathrm{~m}$, $1 \mathrm{H}, \mathrm{Ar}-\mathrm{H}), 8.23(\mathrm{dd}, J=11.0,2.5 \mathrm{~Hz}, 1 \mathrm{H}, \mathrm{Ar}-\mathrm{H}), 8.16(\mathrm{~m}$, $1 \mathrm{H}, \mathrm{Ar}-\mathrm{H}), 7.92(\mathrm{~d}, J=2.8 \mathrm{~Hz}, 1 \mathrm{H}, \mathrm{Ar}-\mathrm{H}), 7.52(\mathrm{~m}, 1 \mathrm{H}, \mathrm{Ar}-$ $\mathrm{H}), 7.07(\mathrm{~d}, J=8.7 \mathrm{~Hz}, 1 \mathrm{H}, \mathrm{Ar}-\mathrm{H}) .{ }^{13} \mathrm{C}$ NMR $(100 \mathrm{MHz}$, DMSO- $\left.d_{6}\right) \delta$ in ppm: $163.2(\underline{\mathrm{C}}=\mathrm{O}), 155.6(\underline{\mathrm{C}}-\mathrm{OH}), 151.5$ $(\mathrm{d}, J=246.5 \mathrm{~Hz}, \underline{\mathrm{C}}-\mathrm{F}), 142.8(\mathrm{~d}, J=8.6 \mathrm{~Hz}, \underline{\mathrm{C}}=\mathrm{C}-\mathrm{F})$, 134.3 (Ar), 133.4 (d, $J=10.4 \mathrm{~Hz}, \underline{\mathrm{C}}=\mathrm{C}-\mathrm{F}), 130.3$ (Ar), 124.1 (Ar), 121.5 (Ar), 121.2 (Ar), 119.9 (Ar), 119.6 (Ar), $111.6(\mathrm{~d}, J=24.8 \mathrm{~Hz}, \underline{\mathrm{C}}=\mathrm{C}-\mathrm{F}) .{ }^{19} \mathrm{~F} \quad \mathrm{NMR} \quad(376 \mathrm{MHz}$, DMSO- $\left.d_{6}\right) \delta$ in ppm: -125.7 (s, 1F, Ar-F); HRMS: m/z $[\mathrm{M}-\mathrm{H}]^{-}$calcd. For $\mathrm{C}_{13} \mathrm{H}_{7} \mathrm{ClFN}_{2} \mathrm{O}_{4}$ : 309.0079; found: 309.0080 .

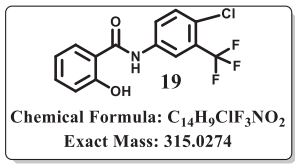

$N$-(4'-chloro-3'-(trifluoromethyl)phenyl)-2-

hydroxybenzamide (19)

White solid, $86 \%$ yield, m.p. $194-196{ }^{\circ} \mathrm{C}$. IR (neat) vmax $\left(\mathrm{cm}^{-1}\right)$ : 3319 (O-H, N-H), $3068(\mathrm{C}-\mathrm{H}), 2923(\mathrm{C}-\mathrm{H}), 1628$ $(\mathrm{C}=\mathrm{O}), 1560,1229,1132,752,691 .{ }^{1} \mathrm{H}$ NMR $(400 \mathrm{MHz}$, DMSO- $\left.d_{6}\right) \delta$ in ppm: $11.45(\mathrm{~s}, 1 \mathrm{H}, \mathrm{OH}), 10.65(\mathrm{~s}, 1 \mathrm{H}, \mathrm{NH})$, $8.33(\mathrm{~d}, \mathrm{~J}=2.3 \mathrm{~Hz}, 1 \mathrm{H}, \mathrm{Ar}-\mathrm{H}), 8.01(\mathrm{dd}, \mathrm{J}=8.7,2.0 \mathrm{~Hz}$, $1 \mathrm{H}, \mathrm{Ar}-\mathrm{H}), 7.88(\mathrm{dd}, \mathrm{J}=7.8,1.4 \mathrm{~Hz}, 1 \mathrm{H}, \operatorname{Ar}-\mathrm{H}), 7.72(\mathrm{~d}, \mathrm{~J}$ $=8.7 \mathrm{~Hz}, 1 \mathrm{H}$, Ar-H) $7.51-7.33(\mathrm{~m}, 1 \mathrm{H}, \mathrm{Ar}-\mathrm{H}), 6.99(\mathrm{~m}$, $2 \mathrm{H}, \mathrm{Ar}-\mathrm{H}) .{ }^{13} \mathrm{C}$ NMR $\left(100 \mathrm{MHz}, \mathrm{DMSO}-d_{6}\right) \delta$ in ppm: $167.2(\underline{\mathrm{C}}=\mathrm{O}), 158.3(\underline{\mathrm{C}}-\mathrm{OH}), 138.3(\mathrm{NH}-\mathrm{C}), 134.2(\mathrm{Ar})$,

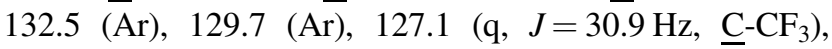
125.9 (Ar), 125.1 (Ar), 123.2 (q, $\left.J=273.2 \mathrm{~Hz}, \underline{\mathrm{CF}}_{3}\right), 119.8$ $\left(\mathrm{q}, J=5.4 \mathrm{~Hz}, \underline{\mathrm{C}}=\mathrm{C}_{-} \mathrm{CF}_{3}\right), 119.6(\underline{\mathrm{C}}-\mathrm{C}=\mathrm{O}), 118.5(\mathrm{Ar})$,
117.6 (Ar). ${ }^{19} \mathrm{~F}$ NMR $\left(376 \mathrm{MHz}\right.$, DMSO- $\left.d_{6}\right) \delta$ in ppm: -61.4 (s, 1F, Ar-C-F); HRMS: m/z [M-H] $]^{-}$calcd. For $\mathrm{C}_{14} \mathrm{H}_{8} \mathrm{ClF}_{3} \mathrm{NO}_{2}$ : 314.0196; found: 314.0191 .

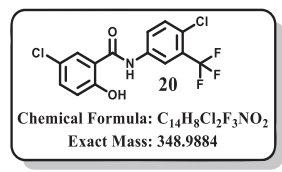

5-Chloro- $N$-(4'-chloro-3'-(trifluoromethyl)phenyl)-2hydroxybenzamide (20)

White solid, $79 \%$ yield, m.p. $229-232{ }^{\circ} \mathrm{C}$. IR (neat) $\nu_{\max }$ $\left(\mathrm{cm}^{-1}\right): 3315(\mathrm{O}-\mathrm{H}, \mathrm{N}-\mathrm{H}), 3087(\mathrm{C}-\mathrm{H}), 2924(\mathrm{C}-\mathrm{H}), 1622$ $(\mathrm{C}=\mathrm{O}), 1109,1024,891,814,655 .{ }^{1} \mathrm{H}$ NMR $(400 \mathrm{MHz}$, DMSO- $\left.d_{6}\right) \delta 11.52(\mathrm{bs}, 1 \mathrm{H}, \mathrm{OH}), 10.67(\mathrm{~s}, 1 \mathrm{H}, \mathrm{NH}), 8.30$ (d, $J=2.3 \mathrm{~Hz}, 1 \mathrm{H}$, Ar-H), $7.99(\mathrm{dd}, J=2.1,8.7 \mathrm{~Hz}, 1 \mathrm{H}$, Ar-H), $7.86(\mathrm{~d}, J=2.7 \mathrm{~Hz}, 1 \mathrm{H}, \mathrm{Ar}-\mathrm{H}), 7.71(\mathrm{~d}, J=8.8 \mathrm{~Hz}$, $1 \mathrm{H}, \mathrm{Ar}-\mathrm{H}), 7.47$ (dd, $J=8.8,2.6 \mathrm{~Hz}, 1 \mathrm{H}, \mathrm{Ar}-\mathrm{H}), 7.03$ (d, $J$ $=8.8 \mathrm{~Hz}, 1 \mathrm{H}, \mathrm{Ar}-\mathrm{H}) .{ }^{13} \mathrm{C}$ NMR $\left(100 \mathrm{MHz}, \mathrm{DMSO}-d_{6}\right) \delta$ in ppm: $165.7(\underline{\mathrm{C}}=\mathrm{O}), 157.0$ ( $\underline{\mathrm{C}}-\mathrm{OH}), 138.1(\mathrm{NH}-\underline{\mathrm{C}}), 133.6$ $(\mathrm{Cl}-\mathrm{C}=\mathrm{C}-\mathrm{C}=\overline{\mathrm{C}}(\mathrm{OH})), 132.4\left(\mathrm{C}\left(\mathrm{CF}_{3}\right)=\mathrm{C}(\mathrm{Cl})-\mathrm{C}\right), 128.9(\mathrm{C}$ $(\mathrm{Cl})-\underline{\mathrm{C}}=\mathrm{C}(\mathrm{CO})), 127.1\left(\mathrm{q}, J=31.0 \mathrm{~Hz}, \underline{\mathrm{C}}-\mathrm{CF}_{3}\right), 125.7(\mathrm{NH}-$ $\mathrm{C}=\underline{\mathrm{C}}-\mathrm{C}), 125.3(\underline{\mathrm{C}}-\mathrm{Cl}), 123.5\left(\mathrm{q}, J=273.2 \mathrm{~Hz}, \underline{\mathrm{CF}}_{3}\right), 123.2$ $\left(\underline{\mathrm{C}}(\overline{\mathrm{Cl}})-\mathrm{C}\left(\mathrm{CF}_{3}\right)\right), \quad 120.1 \quad(\underline{\mathrm{C}}(\mathrm{C}=\mathrm{O}), 119.7 \quad(\mathrm{q}, \bar{J}=5.4 \mathrm{~Hz}$, $\left.\underline{\mathrm{C}}=\mathrm{C}_{-}-\mathrm{CF}_{3}\right), \quad 119.5 \quad(\underline{\mathrm{C}}=\mathrm{C}(\mathrm{OH})-\mathrm{C}(\mathrm{CO})) . \quad{ }^{19} \mathrm{~F} \quad \mathrm{NMR}$ $\left(376 \mathrm{MHz}, \mathrm{DMSO}-d_{6}\right) \delta$ in ppm: -61.4 (s, 1F, Ar-C-F); HRMS: $\mathrm{m} / \mathrm{z}$ [M-H] ${ }^{-}$calcd. For $\mathrm{C}_{14} \mathrm{H}_{7} \mathrm{Cl}_{2} \mathrm{~F}_{3} \mathrm{NO}_{2}: 347.9806$; found: 347.9801 .

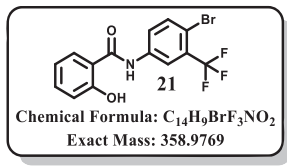

$\mathrm{N}$-(4'-bromo-3'-(trifluoromethyl)phenyl)-2hydroxybenzamide (21)

White solid, $62 \%$ yield, m.p. $190-193{ }^{\circ} \mathrm{C}$. IR (neat) $\nu_{\max }$ $\left(\mathrm{cm}^{-1}\right)$ : $3319(\mathrm{O}-\mathrm{H}, \mathrm{N}-\mathrm{H}), 3073(\mathrm{C}-\mathrm{H}), 2927(\mathrm{C}-\mathrm{H}), 1629$ $(\mathrm{C}=\mathrm{O}), 1555,1134,1024,891,823,758 .{ }^{1} \mathrm{H}$ NMR $\left(400 \mathrm{MHz}, \mathrm{DMSO}-d_{6}\right) \delta$ in ppm: $11.47(\mathrm{~s}, 1 \mathrm{H}, \mathrm{OH}), 10.65$ (s, $1 \mathrm{H}, \mathrm{NH}), 8.32(\mathrm{~d}, J=2.0 \mathrm{~Hz}, 1 \mathrm{H}, \mathrm{Ar}-\mathrm{H}), 7.89(\mathrm{~m}, 3 \mathrm{H}$, $\mathrm{Ar}-\mathrm{H}), 7.45$ (m, 1H, Ar-H), 6.99 (m, 2H, Ar-H). ${ }^{13} \mathrm{C}$ NMR $\left(100 \mathrm{MHz}, \mathrm{DMSO}-d_{6}\right) \delta$ in ppm: $167.3(\underline{\mathrm{C}}=\mathrm{O}), 158.5(\underline{\mathrm{C}}-$ $\mathrm{OH}), 138.7$ (NH-C), 135.7 (Ar), 134.2 (Ar), 129.6 (Ar), $129.0\left(\mathrm{q}, J=30.5, \mathrm{~Hz}, \underline{\mathrm{C}}-\mathrm{CF}_{3}\right), 125.8(\mathrm{Ar}), 123.3(\mathrm{q}, J=$ $\left.273.8 \mathrm{~Hz}, \underline{\mathrm{CF}}_{3}\right), 120.0\left(\mathrm{q}, J=5.7 \mathrm{~Hz}, \underline{\mathrm{C}}=\mathrm{C}_{-} \mathrm{CF}_{3}\right), 119.5$ (Ar), 118.1 (Ar), $117.6(\mathrm{Ar}), 112.7(\mathrm{C}-\mathrm{Br}) .{ }^{19} \mathrm{~F}$ NMR 
(376 MHz, DMSO- $\left.d_{6}\right) \delta$ in ppm: -61.5 (s, 1F, Ar-C-F); HRMS: $\mathrm{m} / \mathrm{z}[\mathrm{M}-\mathrm{H}]^{-}$calcd. For $\mathrm{C}_{14} \mathrm{H}_{8} \mathrm{BrF}_{3} \mathrm{NO}_{2}$ : 357.9691 ; found: 357.9693 .

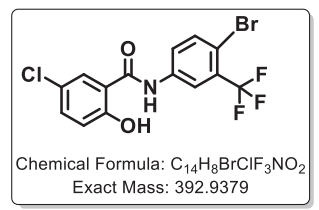

5-Chloro-N-(4'-bromo-3'-(trifluoromethyl)phenyl)-2hydroxybenzamide (22)

White solid, $68 \%$ yield, m.p. $227-230{ }^{\circ} \mathrm{C}$. IR (neat) $\nu_{\max }$ $\left(\mathrm{cm}^{-1}\right)$ : $3318(\mathrm{O}-\mathrm{H}, \mathrm{N}-\mathrm{H}), 3086(\mathrm{C}-\mathrm{H}), 2936(\mathrm{C}-\mathrm{H}), 1631$ $(\mathrm{C}=\mathrm{O}), 1577,1332,1225,1175,762 ， 695 .{ }^{1} \mathrm{H}$ NMR $\left(400 \mathrm{MHz}, \mathrm{DMSO}-d_{6}\right) \delta$ in ppm: $11.55(\mathrm{~s}, 1 \mathrm{H}, \mathrm{OH}), 10.66$ (s, $1 \mathrm{H}, \mathrm{NH}), 8.29$ (d, $J=2.3 \mathrm{~Hz}, 1 \mathrm{H}$, Ar-H), 7.91 (dd, $J=$ 8.8, $2.4 \mathrm{~Hz}, 1 \mathrm{H}, \mathrm{Ar}-\mathrm{H}), 7.87-7.86$ (m, 2H, Ar-H), 7.48 (dd, $J=8.8,2.7 \mathrm{~Hz}, 1 \mathrm{H}, \mathrm{Ar}-\mathrm{H}), 7.03(\mathrm{~d}, J=8.8 \mathrm{~Hz}, 1 \mathrm{H}, \mathrm{Ar}-\mathrm{H})$. ${ }^{13} \mathrm{C}$ NMR (100 MHz, DMSO- $\left.d_{6}\right) \delta$ in ppm: $165.7(\underline{\mathrm{C}}=\mathrm{O})$, 156.9 (ㄷ-OH), 138.5 (NH-C $), 135.8(\mathrm{Br}-\mathrm{C}=\mathrm{C}-\mathrm{C}), 133.6$ $(\mathrm{Cl}-\mathrm{C}=\mathrm{C}-\mathrm{C}(\mathrm{OH})), 129.0\left(\mathrm{q}, J=30.5 \mathrm{~Hz}, \underline{\mathrm{C}}-\mathrm{CF}_{3}\right), 128.9$ $(\underline{\mathrm{C}}=\mathrm{C}-\overline{\mathrm{C}}=\mathrm{O}), 125.8(\mathrm{NH}-\mathrm{C}=\underline{\mathrm{C}}-\mathrm{C}), 123.2(\mathrm{q}, J=273.7 \mathrm{~Hz}$, $\left.\underline{\mathrm{CF}}_{3}\right), 123.1(\underline{\mathrm{C}}-\mathrm{Cl}), 120.2(\underline{\mathrm{C}}-\mathrm{C}=\mathrm{O}), 120.0(\mathrm{q}, J=5.9 \mathrm{~Hz}$, $\left.\underline{\mathrm{C}}=\mathrm{C}_{-} \mathrm{CF}_{3}\right), \quad 119.4 \quad(\underline{\mathrm{C}}-\mathrm{C}(\mathrm{OH})-\mathrm{C}(\mathrm{CO})), 113.0 \quad(\underline{\mathrm{C}}-\mathrm{Br}) .{ }^{19} \mathrm{~F}$ NMR $\left(376 \mathrm{MHz}, \mathrm{DMSO}-d_{6}\right) \delta$ in ppm: $-61.5(\mathrm{~s}, 1 \mathrm{~F}, \mathrm{Ar}-\mathrm{C}-$ F). HRMS: $\mathrm{m} / \mathrm{z}[\mathrm{M}-\mathrm{H}]^{-}$calcd. For $\mathrm{C}_{14} \mathrm{H}_{7} \mathrm{BrClF}_{3} \mathrm{NO}_{2}$ : 391.9301; found: 391.9303 .

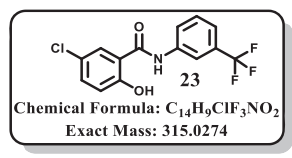

\section{5-Chloro- $N$-(3'-(trifluoromethyl)phenyl)-2-}

hydroxybenzamide (23)

White solid, $80 \%$ yield, m.p. $188-191{ }^{\circ} \mathrm{C}$. IR (neat) $\nu_{\max }$ $\left(\mathrm{cm}^{-1}\right)$ : $3395(\mathrm{O}-\mathrm{H}), 3317(\mathrm{~N}-\mathrm{H}), 2920(\mathrm{C}-\mathrm{H}), 1627(\mathrm{C}=\mathrm{O})$, 1416, 1119, 1022, 894, 771, 663. ${ }^{1} \mathrm{H}$ NMR $(400 \mathrm{MHz}$, DMSO- $\left.d_{6}\right) \delta$ in ppm: $11.67(\mathrm{~s}, 1 \mathrm{H}, \mathrm{OH}), 10.63(\mathrm{~s}, 1 \mathrm{H}, \mathrm{NH})$, 8.20 (s, 1H, Ar-H), 7.94 (m, 2H, Ar-H), 7.61-7.41 (m, 3H, Ar-H), $7.03 \quad(\mathrm{~d}, \quad J=8.5 \mathrm{~Hz}, \quad 1 \mathrm{H}, \quad$ Ar-H $) .{ }^{13} \mathrm{C} \quad \mathrm{NMR}$ $\left(100 \mathrm{MHz}, \mathrm{DMSO}-d_{6}\right) \delta$ in ppm: $165.7(\mathrm{C}=\mathrm{O}), 157.0(\mathrm{C}-$ $\mathrm{OH}), 139.3$ (NH-C), 133.5 (Ar), 130.3 (Ar), 129.9 (q, $J=$ $\left.31.9 \mathrm{~Hz}, \quad \underline{\mathrm{C}}^{-\mathrm{CF}_{3}}\right), \quad 128.9 \quad(\mathrm{C}=\mathrm{C}-\mathrm{C}=\mathrm{O}), 125.6 \quad(\mathrm{q}, \quad J=$ $\left.272.4 \mathrm{~Hz}, \underline{\mathrm{C}} \mathrm{F}_{3}\right), 124.6(\mathrm{C}-\mathrm{Cl}), 123.2,\left(\underline{\mathrm{C}}=\mathrm{C}-\mathrm{CF}_{3}\right), 120.9(\mathrm{q}$, $\left.J=3.8 \mathrm{~Hz}, \underline{\mathrm{C}}=\mathrm{C}_{-}-\mathrm{CF}_{3}\right), 120.2,119.5(\underline{\mathrm{C}}-\mathrm{C}(\mathrm{OH})-\mathrm{C}(\mathrm{CO}))$, $117.2\left(\mathrm{q}, J=3.6 \mathrm{~Hz}, \quad \underline{\mathrm{C}}=\mathrm{C}-\mathrm{CF}_{3}\right) .{ }^{19} \mathrm{~F} \quad \mathrm{~N} M R(376 \mathrm{MHz}$, DMSO- $d_{6}$ ) $\delta$ in ppm: -61.3 (s, 1F, Ar-C-F); HRMS m/z
Calcd for $[\mathrm{M}+\mathrm{H}]^{+} \mathrm{C}_{14} \mathrm{H}_{10} \mathrm{ClF}_{3} \mathrm{NO}_{2}$ is 316.0352 , found 316.0343 .

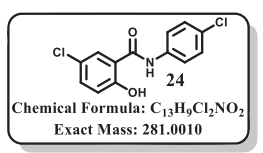

5-Chloro- $N$-(4'-chlorophenyl)-2-hydroxybenzamide (24)

White solid, $81 \%$ yield, m.p. $228-230{ }^{\circ} \mathrm{C}$. IR (neat) $\nu_{\max }$ $\left(\mathrm{cm}^{-1}\right)$ : $3394(\mathrm{O}-\mathrm{H}, \mathrm{N}-\mathrm{H}), 2922(\mathrm{C}-\mathrm{H}), 1611(\mathrm{C}=\mathrm{O}), 1546$, 1216, $1093,815,762,707 .{ }^{1} \mathrm{H}$ NMR (400 MHz, DMSO- $d_{6}$ ) $\delta$ in ppm: $11.76(\mathrm{~s}, 1 \mathrm{H}, \mathrm{OH}), 10.48(\mathrm{~s}, 1 \mathrm{H}, \mathrm{NH}), 7.93(\mathrm{~d}, J$ $=2.6 \mathrm{~Hz}, 1 \mathrm{H}, \mathrm{Ar}-\mathrm{H}), 7.75(\mathrm{~m}, 2 \mathrm{H}, \mathrm{Ar}-\mathrm{H}), 7.44(\mathrm{~m}, 3 \mathrm{H}, \mathrm{Ar}-$ $\mathrm{H}), 7.02(\mathrm{~d}, J=8.8 \mathrm{~Hz}, 1 \mathrm{H}, \mathrm{Ar}-\mathrm{H}) .{ }^{13} \mathrm{C}$ NMR $(100 \mathrm{MHz}$, DMSO- $\left.d_{6}\right) \delta$ in ppm: $165.4(\underline{\mathrm{C}}=\mathrm{O}), 157.1(\underline{\mathrm{C}}-\mathrm{OH}), 137.4$ (Ar), 133.5 (Ar), 129.1 (2C, Ar) 128.9 (Ar), 128.4 (Ar), 123.2 ( $\underline{\mathrm{C}}-\mathrm{Cl}), 122.8$ (2C, Ar), $120.1(\underline{\mathrm{C}}-\mathrm{C}=\mathrm{O}), 119.5$ ( $\underline{\mathrm{C}}=\mathrm{C}$ $(\mathrm{OH})-\mathrm{C}(\mathrm{CO}))$; HRMS: $\mathrm{m} / \mathrm{z} \quad[\overline{\mathrm{M}}-\mathrm{H}]^{-}$calcd. For $\mathrm{C}_{13} \mathrm{H}_{8} \mathrm{Cl}_{2} \mathrm{NO}_{2}$ : 279.9932; found: 279.9934.

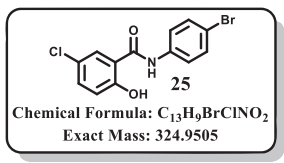

\section{5-Chloro- $N$-(4'-bromophenyl)-2-hydroxybenzamide (25)}

White solid, $87 \%$ yield, m.p. $222-225^{\circ} \mathrm{C}$. IR (neat) $\nu_{\max }$ $\left(\mathrm{cm}^{-1}\right): 3394(\mathrm{O}-\mathrm{H}, \mathrm{N}-\mathrm{H}), 3092(\mathrm{C}-\mathrm{H}), 2922(\mathrm{C}-\mathrm{H}), 1609$ $(\mathrm{C}=\mathrm{O}), 1544,1216,1069,815,761,708 .{ }^{1} \mathrm{H}$ NMR $\left(400 \mathrm{MHz}, \mathrm{DMSO}-d_{6}\right) \delta$ in ppm: $11.76(\mathrm{~s}, 1 \mathrm{H}, \mathrm{OH}), 10.47$ (s, 1H, NH), $7.92(\mathrm{~d}, J=2.6 \mathrm{~Hz}, 1 \mathrm{H}, \mathrm{Ar}-\mathrm{H}), 7.69$ (d, $J=$ $8.8 \mathrm{~Hz}, 2 \mathrm{H}, \mathrm{Ar}-\mathrm{H}), 7.54$ (d, $J=8.8 \mathrm{~Hz}, 2 \mathrm{H}, \mathrm{Ar}-\mathrm{H}), 7.45$ (dd, $J=8.8,2.7 \mathrm{~Hz}, 1 \mathrm{H}, \mathrm{Ar}-\mathrm{H}), 7.02$ (d, $J=8.8 \mathrm{~Hz}, 1 \mathrm{H}, \mathrm{Ar}-\mathrm{H})$. ${ }^{13} \mathrm{C}$ NMR $\left(100 \mathrm{MHz}, \mathrm{DMSO}-d_{6}\right) \delta$ in ppm: $165.4(\underline{\mathrm{C}}=\mathrm{O})$, 157.1 ( $\underline{\mathrm{C}}-\mathrm{OH}), 137.9$ (NH-C), 133.5 (Ar), 132.0 (2C, Ar), 128.9 (Ar), 123.2 (C-Cl), 123.1 (2C, Ar), 120.1 (Ar), 119 (Ar), 116.5 (C-Br); HRMS: m/z [M-H] $]^{-}$calcd. For $\mathrm{C}_{13} \mathrm{H}_{8} \mathrm{BrClNO}_{2}$ : 323.9427; found: 323.9431 .

\section{undefined antibacterial activity}

\section{Bacterial strains and antibiotic susceptibility testing}

The compounds were screened against a bacterial panel consisting of ESKAPE pathogens namely E. coli (ATCC 25922), K. pneumoniae (BAA 1705), A. baumannii (BAA 1605), $P$. aeruginosa (ATCC 27853), and S. aureus (ATCC 29213) 
$[35,36]$. The panel was further expanded to include drugresistant clinical $S$. aureus and Enterococci strains including those resistant to vancomycin and other clinically utilized antibiotics. These strains were procured from Biodefense and Emerging Infections Research Resources Repository/Network on Antimicrobial Resistance in Staphylococcus aureus/ American Type Culture Collection (BEI/NARSA/ATCC, USA) and routinely cultivated on MHA and MHBII (Difco). Before starting the experiment, single colony was picked from MHA plate, inoculated in Muller-Hinton broth (MHB, Difco) and incubated at $37^{\circ} \mathrm{C}$ for overnight to get the starter culture.

\section{Antibiotic susceptibility testing}

Antibiotic susceptibility testing was carried out by broth microdilution assay. Test compounds were prepared in DMSO as stock solutions $(10 \mathrm{mg} / \mathrm{mL})$ [37]. Bacterial cultures were inoculated in MHB. Optical density (OD) of the cultures was measured at the wavelength of $600 \mathrm{~nm}$ followed by dilution to achieve $\sim 10^{6} \mathrm{CFU} / \mathrm{ml}$. The concentrations of test compounds used in the study ranged from 64 to $0.5 \mathrm{mg} / \mathrm{L}$ in serially diluted fashion in DMSO from stock solutions and $2.5 \mu \mathrm{L}$ of each concentration was added to each well of a 96-well microtiter plate (Polypropylene, Corning Inc., Corning, USA). Later, $97.5 \mu \mathrm{L}$ of bacterial suspension in MHB medium was added to each well containing the test compound. Two controls were also included, i.e., cells alone and media alone (without compound + cells) and plates were incubated at $37{ }^{\circ} \mathrm{C}$ for $16-18 \mathrm{~h}$. MIC values were observed by the absence or presence of visible growth. For each compound, MIC determinations were carried independently three times using duplicate samples.

\section{Cell cytotoxicity assay}

Cell toxicity was performed against Vero cells using the MTT assay [38]. In all, $\sim 10^{3}$ cells/well were seeded in 96well plate and incubated at $37{ }^{\circ} \mathrm{C}$ in an $5 \% \mathrm{CO}_{2}$ atmosphere. After $24 \mathrm{~h}$, compound was added ranging from 100 to $12.5 \mu \mathrm{g} / \mathrm{mL}$ concentration and incubated for $72 \mathrm{~h}$. After the incubation was over, MTT was added in each well, incubated at $37^{\circ} \mathrm{C}$ for further $4 \mathrm{~h}$, residual medium was discarded, $0.1 \mathrm{~mL}$ of DMSO was added to solubilize the formazan crystals, and OD was taken at $540 \mathrm{~nm}$ for the calculation of $\mathrm{CC}_{50} \cdot \mathrm{CC}_{50}$ is defined as the lowest concentration of compound that leads to a $50 \%$ reduction in cell viability. Doxorubicin was used as positive control and each experiment was repeated in triplicate.

\section{Drug interaction with FDA-approved drugs}

Interaction of $\mathbf{2 2}$ with FDA-approved drugs was tested by checkerboard method [39]. Serial two-fold dilutions of each drug were freshly prepared prior to testing. 20 was two-fold diluted along abscissa, while the antibiotics were serially diluted along ordinate in 96-well microtiter plate. Then, $95 \mu \mathrm{L}$ of $\sim 10^{5} \mathrm{CFU} / \mathrm{mL}$ was added to each well and plates were incubated at $37^{\circ} \mathrm{C}$ for $24 \mathrm{~h}$. After the incubation, the $\Sigma$ FICs (fractional inhibitory concentrations) were calculated as follows: $\Sigma$ FIC $=$ FIC A + FIC $\mathrm{B}$, where FIC A is the MIC of drug A in the combination/ MIC of drug A alone and FIC B is the MIC of drug B in the combination/MIC of drug $\mathrm{B}$ alone. The combination is considered synergistic when the EFIC is $\leq 0.5$, indifferent when the $\Sigma F I C$ is $>0.5-4$, and antagonistic when the $\Sigma F I C$ is $>4$.

\section{Time-kill kinetics}

The bactericidal activity was assessed by time-kill method [35]. Briefly, S. aureus ATCC 29213 was diluted to $\sim 10^{6}$ $\mathrm{cfu} / \mathrm{mL}$, cells were treated with individual inhibitors along with appropriate controls at $1 \times$ and $10 \times$ MIC followed by incubation at $37^{\circ} \mathrm{C}$ for $24 \mathrm{~h}$. A $0.1 \mathrm{~mL}$ sample was removed at various time points, serial ten-fold dilutions in $0.9 \mathrm{~mL}$ of PBS and $0.1 \mathrm{~mL}$ of the respective dilution were spread on an MHA. The plates will be incubated at $37^{\circ} \mathrm{C}$ for $24 \mathrm{~h}$ and colonies enumerated. Kill curves were constructed by counting the colonies from plates and plotting the $\mathrm{cfu} / \mathrm{mL}$ of surviving bacteria at each time point in the presence and absence of compounds.

\section{Determination of activity of 22 against S. aureus biofilm}

The determination of $\mathbf{2 2}$ anti-biofilm activity was performed as described earlier [35]. Briefly, S. aureus ATCC 29213 were grown overnight in 1\% TSB with shaking (180 RPM) at $37^{\circ} \mathrm{C}$. The overnight culture was diluted in fresh TSB broth (1:100) and $0.2 \mathrm{~mL}$ of freshly diluted culture was transferred into 96 -well polystyrene flat bottom plate, covered with adhesive foil lid for maintaining low oxygen, and incubated in static condition for $48 \mathrm{~h}$ at $37^{\circ} \mathrm{C}$. After incubation, media was decanted and plate was rinsed gently three times with the 1X PBS (pH 7.4) to remove the planktonic bacteria. Plates were refilled with TSB with different drug concentration and incubated for $24 \mathrm{~h}$ at $37^{\circ} \mathrm{C}$. After drug treatment, the media was decanted, washed three times with $1 \mathrm{X}$ PBS (pH 7.4), and biofilm was fixed by incubating the plate at $60{ }^{\circ} \mathrm{C}$ for $1 \mathrm{~h}$. After fixing, the biofilm is stained by $0.06 \%$ crystal violet for $10 \mathrm{~min}$, rinsed with PBS, and dried at room temperature. For quantification of biofilm, the bound crystal violet was eluted by $30 \%$ acetic acid $(0.2 \mathrm{~mL})$. Absorbance was taken on microtiter plate reader at $600 \mathrm{~nm}$ for biofilm quantification. 
Acknowledgements We thank CSIR-Central Drug Research Institute, India, for funding this work. JL and SBA acknowledge Council of Scientific and Industrial Research (CSIR), India for research fellowships, while GK thanks DST-INSPIRE and AA thanks UGC for their fellowships. We acknowledge CDRI SAIF Division for the analytical data. The ORCID ID for GK is 0000-0002-2820-9573, AA is 00000002-7892-4997, DNR is 0000-0001-9762-9160, and SC is 00000001-8823-607. This manuscript bears CDRI Communication No: 10298. The following reagents were provided by the Network on Antimicrobial Resistance in Staphylococcus aureus (NARSA) for distribution by BEI Resources, NIAID, NIH: NR 119, NR 100, NR 10129, NR 10198, NR 10192, NR 10191, NR 10193, NR 10186, NR 10194, VRS 1, VRS 4, and VRS 12.

\section{Compliance with ethical standards}

Conflict of interest The authors declare no competing interests.

Publisher's note Springer Nature remains neutral with regard to jurisdictional claims in published maps and institutional affiliations.

\section{References}

1. Prestinaci F, Pezzotti P, Pantosti A. Antimicrobial resistance: a global multifaceted phenomenon. Pathog Glob Health. 2015;109:309-18. https://doi.org/10.1179/2047773215Y. 0000000030.

2. Loomba PS, Taneja J, Mishra B. Methicillin and vancomycin resistant $S$. aureus in hospitalized patients. J Glob Infect Dis. 2010;2:275-83. https://doi.org/10.4103/0974-777x.68535.

3. Fridkin SK. Vancomycin-intermediate and -resistant Staphylococcus aureus: what the infectious disease specialist needs to know. Clin Infect Dis. 2001;32:108-15. https://doi.org/10.1086/ 317542 .

4. Cong Y, Yang S, Rao X. Vancomycin resistant Staphylococcus aureus infections: a review of case updating and clinical features. J Adv Res. 2020;21:169-76. https://doi.org/10.1016/j.jare.2019. 10.005 .

5. Fisher RA, Gollan B, Helaine S. Persistent bacterial infections and persister cells. Nat Rev Microbiol. 2017;15:453-64. https://doi. org/10.1038/nrmicro.2017.42.

6. Bhattacharya M, Wozniak DJ, Stoodley P, Hall-Stoodley L. Prevention and treatment of Staphylococcus aureus biofilms. Expert Rev Anti Infect Ther. 2015;13:1499-516. https://doi.org/10.1586/ 14787210.2015.1100533.

7. Waters EM, Rowe SE, O'Gara JP, Conlon BP. Convergence of Staphylococcus aureus persister and biofilm research: can biofilms be defined as communities of adherent persister cells? PLoS Pathog. 2016;12:e1006012 https://doi.org/10.1371/journal.ppat. 1006012.

8. Tattevin P, Schwartz BS, Graber CJ, Volinski J, Bhukhen A, Bhukhen A. et al. Concurrent epidemics of skin and soft tissue infection and bloodstream infection due to community-associated methicillin-resistant Staphylococcus aureus. Clin Infect Dis. 2012;55:781-8. https://doi.org/10.1093/cid/cis527.

9. Spellberg B. The future of antibiotics. Crit Care. 2014;18:228 https://doi.org/10.1186/cc13948.

10. Butler MS, Paterson DL. Antibiotics in the clinical pipeline in October 2019. J Antibiot. 2020;73:329-64. https://doi.org/10. 1038/s41429-020-0291-8.

11. Lowy FD. Antimicrobial resistance: the example of Staphylococcus aureus. J Clin Invest. 2003;111:1265-73. https://doi.org/ 10.1172/jci18535.
12. Fomovska A, Wood RD, Mui E, Dubey JP, Ferreira LR, Hickman MR. et al. Salicylanilide inhibitors of Toxoplasma gondii. J Med Chem. 2012;55:8375-91. https://doi.org/10.1021/jm3007596.

13. Macielag MJ, Demers JP, Fraga-Spano SA, Hlasta DJ, Johnson SG, Kanojia RM. et al. Substituted salicylanilides as inhibitors of two-component regulatory systems in bacteria. J Med Chem. 1998;41:2939-45. https://doi.org/10.1021/jm9803572.

14. De La Fuente R, Sonawane ND, Arumainayagam D, Verkman AS. Small molecules with antimicrobial activity against $E$. coli and $P$. aeruginosa identified by high-throughput screening. Br $\mathrm{J}$ Pharm. 2006;149:551-9. https://doi.org/10.1038/sj.bjp.0706873.

15. Imramovský A, Vinšová J, Férriz JM, Buchta V, Jampílek J. Salicylanilide esters of N-protected amino acids as novel antimicrobial agents. Bioorg Med Chem Lett. 2009;19:348-51. https://doi.org/10.1016/j.bmcl.2008.11.080.

16. Lee I-Y, Gruber TD, Samuels A, Yun M, Nam B, Kang M. et al. Structure-activity relationships of antitubercular salicylanilides consistent with disruption of the proton gradient via proton shuttling. Bioorg Med Chem. 2013;21:114-26. https://doi.org/10. 1016/j.bmc.2012.10.056.

17. Al-Gareeb A, Gorial F, Mahmood A. The anti-rheumatoid activity of niclosamide in collagen-induced arthritis in rats. Arch Rheumatol. 2019;34:426-33. https://doi.org/10.5606/ArchRheumatol. 2019.7100 .

18. Chai WH, Li YR, Lin SH, Chao YH, Chen CH, Chan PC. et al. Antihelminthic niclosamide induces autophagy and delayed apoptosis inhuman non-small lung cancer cells in vitro and in vivo. Anticancer Res. 2020;40:1405-17. https://doi.org/10. 21873/anticanres.14082.

19. Xu J, Shi PY, Li H, Zhou J. Broad spectrum antiviral agent niclosamide and its therapeutic potential. ACS Infect Dis. 2020;6:909-15. https://doi.org/10.1021/acsinfecdis.0c00052.

20. Xu J, Berastegui-Cabrera J, Chen H, Pachón J, Zhou J, SánchezCéspedes J. Structure-activity relationship studies on diversified salicylanilide derivatives as potent inhibitors of human adenovirus infection. J Med Chem. 2020;63:3142-60. https://doi.org/10. 1021/acs.jmedchem.9b01950.

21. Rajamuthiah R, Fuchs BB, Jayamani E, Kim Y, Larkins-Ford J, Conery A. et al. Whole animal automated platform for drug discovery against multi-drug resistant Staphylococcus aureus. PLoS One. 2014;9:e89189. https://doi.org/10.1371/journal.pone. 0089189.

22. Rajamuthiah R, Fuchs BB, Conery AL, Kim W, Jayamani E, Kwon B. et al. Repurposing salicylanilide anthelmintic drugs to combat drug resistant Staphylococcus aureus. PLoS One. 2015;10:e0124595. https://doi.org/10.1371/journal.pone.0124595.

23. Mohammad H, AbdelKhalek A, Abutaleb NS, Seleem MN. Repurposing niclosamide for intestinal decolonization of vancomycin-resistant enterococci. Int $\mathrm{J}$ Antimicrob Agents. 2018;51:897-904. https://doi.org/10.1016/j.ijantimicag.2018.02. 003.

24. Escobar IE, White A, Kim W, Mylonakis E. New antimicrobial bioactivity against multidrug-resistant gram-positive bacteria of kinase inhibitor IMD0354. Antibiotics. 2020;9:665 https://doi.org/ 10.3390/antibiotics9100665.

25. Andrews P, Thyssen J, Lorke D. The biology and toxicology of molluscicides, Bayluscide. Pharm Ther. 1982;19:245-95. https:// doi.org/10.1016/0163-7258(82)90064-x.

26. Xu J, Pachón-Ibáñez ME, Cebrero-Cangueiro T, Chen H, Sánchez-Céspedes J, Zhou J. Discovery of niclosamide and its Oalkylamino-tethered derivatives as potent antibacterial agents against carbapenemase-producing and/or colistin resistant Enterobacteriaceae isolates. Bioorg Med Chem Lett. 2019;29:1399-402. https://doi.org/10.1016/j.bmcl.2019.03.032.

27. Meanwell NA. Fluorine and fluorinated motifs in the design and application of bioisosteres for drug design. J Med Chem. 
2018;61:5822-80. https://doi.org/10.1021/acs.jmedchem. $7 \mathrm{~b} 01788$.

28. Hevey R. The role of fluorine in glycomimetic drug design. Chem Eur J. 2021;27:2240-53. https://doi.org/10.1002/chem. 202003135

29. Inoue M, Sumii Y, Shibata N. Contribution of organofluorine compounds to pharmaceuticals. ACS Omega. 2020;5:10633-40. https://doi.org/10.1021/acsomega.0c00830.

30. Gade ND, Qazi MS. Fluoroquinolone therapy in Staphylococcus aureus infections: where do we stand? J Lab Physicians. 2013;5:109-12. https://doi.org/10.4103/0974-2727.119862.

31. Piccionello AP, Pibiri I, Buscemi S, Pace A. Recent development in fluorinated antibiotics. Fluorine in Life Sciences: Pharmaceuticals, Medicinal Diagnostics, and Agrochemicals. Elsevier Inc. 2019. https://doi.org/10.1016/B978-0-12-812733-9.00005-2.

32. Kocyigit I, Dortdudak S, Sipahioglu M, Unal A, Yucel HE, Tokgoz B. et al. Levofloxacin-induced delirium: is it a dangerous drug in patients with renal dysfunction? Ren Fail. 2012;34:634-6. https://doi.org/10.3109/0886022X.2012.660855.

33. Mendes RE, Deshpande LM, Jones RN. Linezolid update: stable in vitro activity following more than a decade of clinical use and summary of associated resistance mechanisms. Drug Resist Updat. 2014;17:1-12. https://doi.org/10.1016/j.drup. 2014.04.002.
34. Gu B, Kelesidis T, Tsiodras S, Hindler J, Humphries RM. The emerging problem of linezolid-resistant Staphylococcus. J Antimicrob Chemother. 2013;68:4-11. https://doi.org/10.1093/jac/ dks354.

35. Thakare R, Shukla M, Kaul G, Dasgupta A, Chopra S. Repurposing disulfiram for treatment of Staphylococcus aureus infections. Int J Antimicrob Agents. 2019;53:709-15. https://doi.org/ 10.1016/j.ijantimicag.2019.03.024.

36. Reddy DN, Singh S, Ho CMW, Patel J, Schlesinger P, Rodgers S. et al. Design, synthesis, and biological evaluation of stable $\beta(6.3)$ Helices: discovery of non-hemolytic antibacterial peptides. Eur J Med Chem. 2018;149:193-210. https://doi.org/10.1016/j.ejmech. 2018.02.057.

37. CLSI. Performance standards for antimicrobial susceptibility testing; twenty-first informational supplement. CLSI document M100-S21. Wayne, PA: Clinical and Laboratory Standards Institute; 2012.

38. Twentyman PR, Luscombe M. A study of some variables in a tetrazolium dye (MTT) based assay for cell growth and chemosensitivity. Br J Cancer. 1987;56:279-85. https://doi.org/10.1038/ bjc. 1987.190.

39. Odds FC. Synergy, antagonism, and what the chequerboard puts between them. J Antimicrob Chemother. 2003;52:1 https://doi. org/10.1093/jac/dkg301. 